\title{
Application of Weighted Analog Intensity Prediction (WAIP) guidance on Philippine tropical cyclone events
}

\author{
Robb P. Gile ${ }^{1, *}$, John Carlo S. Sugui ${ }^{1}$, Juanito S. Galang ${ }^{1}$, Esperanza O. Cayanan ${ }^{1}$, Hsiao-Chung Tsai ${ }^{2}$, \\ Yung-Lan Lin ${ }^{3}$, Ai-Mei Chia ${ }^{3}$, Ping-Yu Lin ${ }^{3}$, Kuo-Chen Lu ${ }^{3}$, and Ben Jong-Dao Jou ${ }^{4}$ \\ ${ }^{1}$ Philippine Atmospheric, Geophysical and Astronomical Services Administration, Department of Science and Technology, \\ Diliman, Quezon City, Philippines \\ ${ }^{2}$ Department of Water Resources and Environmental Engineering, Tamkang University, New Taipei City, Taiwan \\ ${ }^{3}$ Weather Forecast Center, Central Weather Bureau, Taipei City, Taiwan \\ ${ }^{4}$ Department of Atmospheric Sciences, National Taiwan University, Taipei City, Taiwan
}

\section{Article history: \\ Received 25 June 2020 \\ Revised 1 March 2021 \\ Accepted 3 March 2021}

Keywords:

Intensity forecast, Philippine tropical cyclones, Weighted analog technique

\section{Citation:}

Gile, R. P., J. C. S. Sugui, J. S. Galang, E. O. Cayanan, H.-C. Tsai, Y.-L. Lin, A.-M. Chia, P.-Y. Lin, K.-C. Lu, and B. J.-D. Jou, 2021: Application of Weighted Analog Intensity Prediction (WAIP) guidance on Philippine tropical cyclone events. Terr. Atmos. Ocean. Sci., 32, 669-691, doi: 10.3319/TAO.2021.03.03.01

\begin{abstract}
The tropical cyclone (TC) intensity forecast from the Weighted Analog Intensity Prediction (WAIP) was evaluated using 63 Philippine TC cases from 2014 to 2017 to determine its applicability as baseline intensity forecast guidance of the Philippine Atmospheric, Geophysical and Astronomical Services Administration (PAGASA). The method generates a rank-weighted average of intensity evolutions of 10 historical analogs from the 1945 to 2014 Joint Typhoon Warning Center best tracks that closely resemble the PAGASA official forecast track and initial intensity at the time the forecast is generated. WAIP proved to be more skillful in providing intensity forecast at 12 to $96 \mathrm{~h}$ and less skillful at $120 \mathrm{~h}$ relative to persistence. Verification revealed that WAIP had significantly smaller mean absolute error and consistently smaller intensity biases up to $96 \mathrm{~h}$. However, the small sample size at $96 \mathrm{~h}$ due to the limitations in the extent of the observed track and reference track forecast from PAGASA suggests that the result may not fully represent the model performance within the Philippine Area of Responsibility at $96 \mathrm{~h}$. The probability distribution of intensities at 36,72, and $96 \mathrm{~h}$ predicted by the model showed that the statistical model may not fully capture the full range of the observed intensities or the extreme values, with the model struggling to predict lower range of intensity values with increasing forecast intervals. Three TC cases are presented to emphasize the model dependence on the accuracy of the reference track forecast and the number and representativeness of available historical analogs for a particular forecast scenario.
\end{abstract}

\section{INTRODUCTION}

The provision of the official five-day tropical cyclone (TC) intensity forecast is made possible by significant advances in statistical, dynamical, and statistical-dynamical TC intensity forecast guidance products over the years (DeMaria et al. 2014). One of the factors that resulted in the improved intensity forecast guidance is the improvement in the track forecast guidance because intensity change is dependent on the environment which a TC is expected to move. For instance, intensity evolution is different for westward moving TCs over warm oceans and low verti-

\footnotetext{
* Corresponding author

E-mail:rpgile@pagasa.dost.gov.ph
}

cal wind shear than for TCs with a recurving track moving towards colder oceans and high-shear environment of the midlatitude region. Furthermore, the timing and location of landfall are both critical in intensity prediction (Tsai and Elsberry 2015a).

Situated in the Western North Pacific (WNP) basin, which is the most climatologically active TC basin (Maue 2011) and with the highest frequency of landfalling TCs (Weinkle et al. 2012), the Philippines remains one of the countries that are most susceptible to natural disasters (Kirch et al. 2017). While the state weather bureau Philippine Atmospheric, Geophysical and Astronomical Services Administration (PAGASA) provides intensity forecast in terms of TC category (i.e., Tropical Storm, Typhoon, etc.), 
intensity forecast for TCs within its area of responsibility in terms of either central pressure or maximum sustained winds is presently not issued. However, with other models and tools relying on accurate intensity forecast, the state weather bureau is planning to introduce a 5-day quantitative TC intensity forecast. To accomplish this, PAGASA meteorologists need to have access to various intensity guidance models whether statistical, dynamical, statistical-dynamical, or ensemble. Tsai and Elsberry (2014) developed a five-day weighted analog intensity technique for WNP TCs known as Weighted Analog Intensity Prediction (WAIP). Based on the "situation-dependent" intensity skill metric (SDIP) for WNP TCs (Elsberry and Tsai 2014), historical analogs with similar tracks and initial intensities as the TC of interest were derived from the best track dataset of the Joint Typhoon Warning Center (JTWC) from 1945 to 2009 with the premise that the TC track is the primary determinant of the intensity on a five-day timescale or longer. The technique generates an intensity forecast from the weighted average of the intensity evolutions of the 10 historical analogs that closely match a reference track forecast and initial intensity of the TC of interest provided by the end user of WAIP which is usually a TC warning center. In the formulation of the intensity forecast, a linearly increasing weighting factor is used in calculating the average track difference with the 72 -h to 120 -h portion of the track having twice as much weight as the 0 -h to 72 -h portion to give higher rankings to historical analogs with similar timings and position of landfall or recurvature. In addition to intensity forecast, a corresponding weighted intensity spread at each 12-h interval among the 10 analogs is also provided.

Unlike dynamical model guidance and statisticaldynamical techniques that reflect the intensity evolution along the track forecast of the numerical weather prediction (NWP) models, which may or may not be similar to the reference track forecast, WAIP provides the forecaster an intensity forecast that represents the track forecast of the TC warning center. Moreover, compared to dynamical and statistical-dynamical models, WAIP can be locally and quickly run using significantly lower computation resources such as desktop workstations. Lastly, the usability of the model and the information it provides can be extended further. For instance, like the approach of Tsai and Chen (2010), the WAIP can be used to determine the representative analogs of a particular official track forecast. The corresponding observed rainfall over the Philippines during the passage of these analogs can be extracted and used to provide information on the potential rainfall associated with the official track forecast of an approaching TC.

The performance of WAIP against both official JTWC forecast (Tsai and Elsberry 2014) and several numerical model guidance (Tsai and Elsberry 2016) makes the technique a viable intensity forecast guidance for operational use. Since then, a seven-day version (Tsai and Elsberry 2015a) has been developed as the JTWC explored the possibility of extending their TC forecast up to seven days, among other developments (Tsai and Elsberry 2015b, 2017a, 2018, 2019). In addition, the algorithm has also been applied to the Atlantic basin and was found to be a feasible guidance for seven-day intensity forecasts that would improve the intensity forecasts of the National Hurricane Center at 4-5day intervals (Tsai and Elsberry 2015b, 2017b).

The advantages mentioned in this study suggest the potential applicability of WAIP as an intensity guidance model in the Philippines, especially as a baseline forecast guidance. However, to increase the confidence of forecasters in using the intensity forecasts of WAIP in an operational setting, it is imperative that operational meteorologists need to have an understanding on the forecast performance and limitations of the model when applied within PAGASA's forecast area. Furthermore, the usage of tropical cyclone datasets that follow 1-minute wind averaging in the development, bias correction, and independent testing of WAIP means that the intensity guidance needs to be evaluated if used operationally in warning centers such as PAGASA that utilize 10-minute wind averaging times.

This study aims to provide a preliminary insight on the performance of the seven-day version of WAIP model in providing intensity forecasts for TCs within the Philippine Area of Responsibility (PAR) under a 10-minute wind averaging setup. The next section briefly describes the model and methodology employed for the forecast verification. Section 3 presents the results of the verification, selected TC cases, and related discussions. The summary of the study and concluding remarks are given in section 4 .

\section{DATA AND METHODS}

\subsection{Model Development and Information}

The WAIP (Tsai and Elsberry 2014) is an analog model that provides a 5-day forecast intensity guidance based on the reference track forecast of the end user. The model matches the reference track forecast with ten historical analogs from the 1945 - 2009 best track dataset of the JTWC for the WNP basin that closely resembles the reference track forecast and the initial intensity of the TC being forecast (target TC). The intensity forecast of the model is derived from the intensity evolutions of the selected analogs.

Chosen from the JTWC best track dataset, the candidate analogs that occurred within \pm 30 days of the current date are ranked based on the average track difference $d_{T}$ between the target TC and the candidate analog (unit: degrees) and the difference in the initial intensity $d_{V}$ of the target TC and the candidate analog (unit: knots). The average track difference between the forecast positions from the reference track forecast of the target TC at time $t$ and the corresponding best track positions in the candidate analog TC is calculated with a linearly varying weighting factor of 1.0 at initial 
time to 2.0 at $72 \mathrm{~h}$ and a constant weighting factor of 2.0 at the 72 to $120 \mathrm{~h}$ interval. Tsai and Elsberry (2014) noted that the higher weighting factor at 72 to $120 \mathrm{~h}$ period was introduced in WAIP to give higher rankings to analog tracks with similar landfall or recurvature positions and timings.

The analogs are ranked in ascending order according to $d_{T}\left(\operatorname{Rank}_{\mathrm{T}}\right)$ and $d_{V}\left(\operatorname{Rank}_{\mathrm{V}}\right)$. The final ranking of the candidate analogs is determined according to

$\operatorname{Rank}_{\text {analog }}=\mathrm{W}_{\mathrm{T}}\left(\operatorname{Rank}_{\mathrm{T}}\right)+\mathrm{W}_{\mathrm{V}}\left(\operatorname{Rank}_{\mathrm{V}}\right)$

where the weighting factors $\mathrm{W}_{\mathrm{T}}$ and $\mathrm{W}_{\mathrm{V}}$ are relative weighting factors for the track-based ranking and initial intensitybased ranking. In Tsai and Elsberry (2014), $\mathrm{W}_{\mathrm{T}}$ and $\mathrm{W}_{\mathrm{V}}$ are pegged at 0.8 and 0.2 , respectively. Of the candidate analogs, the selection is limited to 10 analogs because the selection of larger number of analogs may be difficult when the ranking is based on the similarity to the reference track forecast, initial intensity difference, and occurrence within \pm 30 days. The weighted mean intensity forecast $V_{w}$ at each time $t$ is calculated using

$V_{w}=\sum_{i=1}^{n}\left(w_{i} \cdot V_{i}\right) / \sum_{i=1}^{n} w_{i}$

where $V_{i}$ is the intensity of the $i$-th track analog and $w_{i}=\left(1 / d_{T, i}\right) / \sum_{i=1}^{n}\left(1 / d_{T, i}\right)$. The weighting factor $w_{i}$ allows the model to give greater weight to those analogs that most closely match the reference track forecast. The resulting intensity forecast is provided in 12-h intervals up to $120 \mathrm{~h}$. In the five-day WAIP, a training dataset using JTWC official forecasts from 2010 to 2012 season was used to perform bias correction to the raw intensity forecast of the model. The bias correction is applied to the raw intensity forecast to come up with a final intensity forecast.

Tsai and Elsberry (2015a) extended the intensity guidance from five days to seven days as JTWC explored the capability of issuing seven-day track forecasts for WNP TCs. The extended version of WAIP shares the same setup as the five-day version except that a development sample from the 2000 - 2009 season was used for intensity bias correction. Independent samples from the 2010 - 2014 season revealed that the intensity mean absolute errors (MAE) and correlation coefficients of the WAIP forecast with the verifying intensities practically remained constant in the 120 -h to 168 -h intervals. More information about the model development is provided in Elsberry and Tsai (2014) for the original SDIP, Tsai and Elsberry (2014) for the five-day WAIP, and Tsai and Elsberry (2015a) for the seven-day WAIP.

This study investigated the performance of the intensity forecast of the seven-day version of WAIP. Although Tsai and Elsberry $(2014,2015 a)$ noted that the 1945 - 2009 JTWC best track dataset was used during the development and verification of the model, the operational version of WAIP that was investigated in this study also utilizes 2010 - 2014 JTWC best track files in addition to the 1945 - 2009 dataset. The inclusion of the 2010 - 2014 best tracks was made to increase the number of historical databases used by WAIP when it was adopted by the Central Weather Bureau (CWB) in 2015 (Tsai 2020, personal communication). The said model is fully embedded (i.e., not operating as an individual model) and can only be operated by PAGASA meteorologists through the PAGASA Integrated System for Typhoon Operations (PISTON). Originally developed as the Typhoon Analysis and Forecasting Integration System (TAFIS) by the CWB, PISTON aims to automate and optimize much of the tropical cyclone forecast processes. PISTON was transferred to and customized by PAGASA under a collaboration program between the two centers between 2017 and 2019. The system is akin to other decision support platforms such as the Automated Tropical Cyclone Forecasting System (Sampson and Schrader 2000) of the JTWC and the Tropical Cyclone Information Processing System (Wong and Choy 2018) of the Hong Kong Observatory (HKO). Unit conversion are performed within the system as PISTON uses meters per second $\left(\mathrm{m} \mathrm{s}^{-1}\right)$ as unit of measurement for winds while the WAIP model uses nautical miles per hour or knots $(\mathrm{kt})$.

\subsection{Verification Using Philippine Tropical Cyclones from 2014 to 2017}

For this study, the performance of WAIP was investigated using 63 TC cases that were given domestic names by PAGASA between the period of January 2014 and December 2017. The sample cases were WNP TC events that occurred within the PAR, the forecast area assigned by the World Meteorological Organization (WMO) to the state weather bureau for tropical cyclone warnings in the offshore waters of the Philippines. This region is demarcated by rhumb lines connecting the coordinates $5^{\circ} \mathrm{N} 115^{\circ} \mathrm{E}, 15^{\circ} \mathrm{N} 115^{\circ} \mathrm{E}, 21^{\circ} \mathrm{N}$ $120^{\circ} \mathrm{E}, 25^{\circ} \mathrm{N} 120^{\circ} \mathrm{E}, 25^{\circ} \mathrm{N} 135^{\circ} \mathrm{E}$, and $5^{\circ} \mathrm{N} 135^{\circ} \mathrm{E}$.

Figure la presents the extent of the PAR and the tracks of sample TC cases that were investigated in this study. Nearly all TC cases that were used in this study had any of the three track orientations - (1) ESE-WNW-oriented track crossing the archipelago (with most of them emerging over the West Philippine Sea), (2) SE-NW-oriented track crossing Taiwan-Ryukyus region and entirely missing the Philippines), and (3) non-landfalling tracks due to recurvature far from land or premature weakening into a remnant low. Figure $1 \mathrm{~b}$ shows that most of the best track positions of the 63 TC cases within the PAR region had an initial intensity falling within the typhoon category (33 to $61 \mathrm{~m} \mathrm{~s}^{-1}$ ), while best track positions having initial intensities under tropical depression and tropical storm categories had similar frequency. In terms of observed changes in maximum 

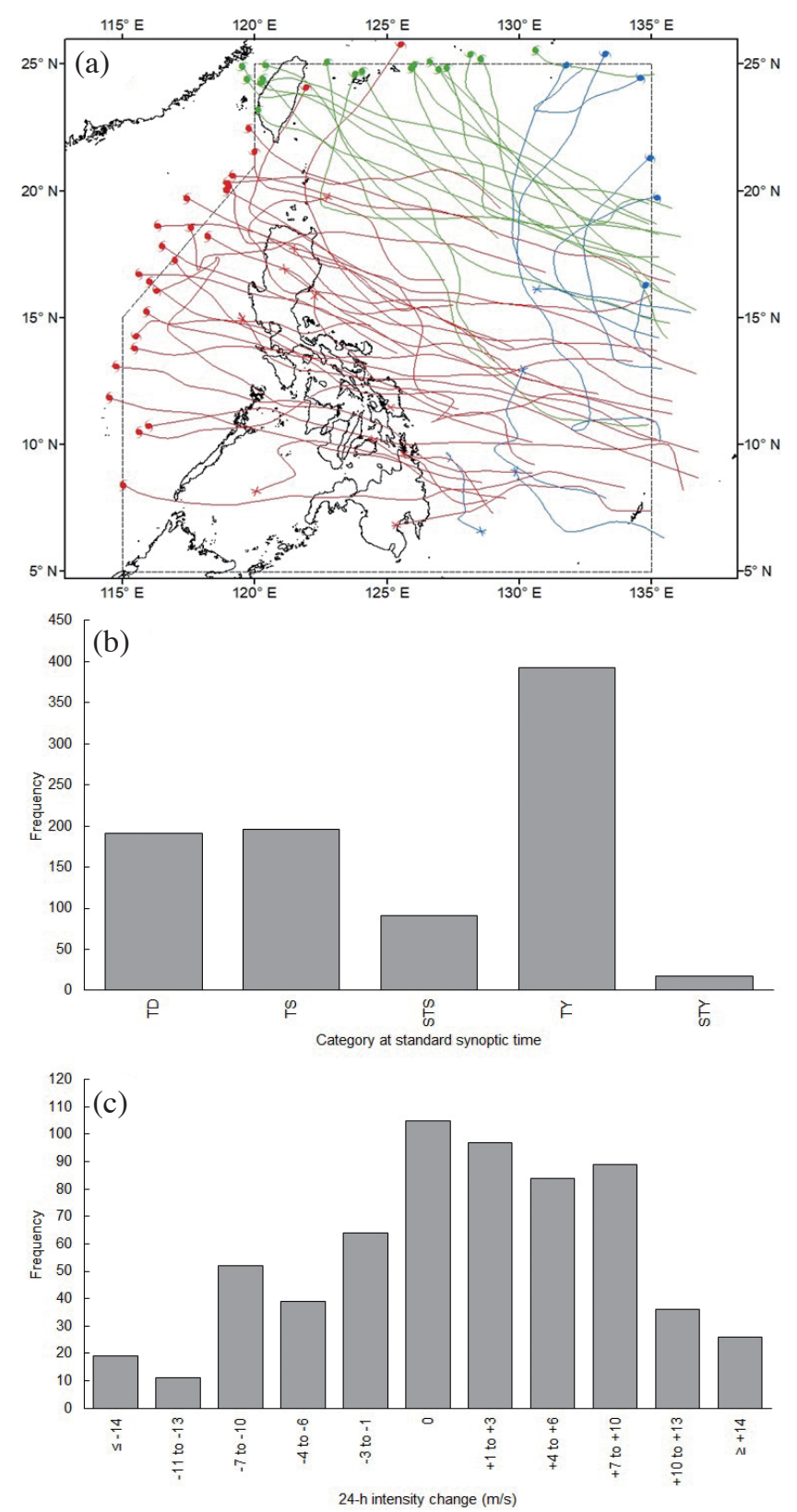

Fig. 1. (a) PAGASA best track of TCs that occurred within the PAR region between January 2014 and December 2017. The extent of the PAR is marked by the dashed six-sided polygon enclosing the Philippines, Taiwan, and Sabah. Red, green and blue tracks indicate TCs that crossed the Philippines, made landfall in Taiwan/Ryukyus without crossing the Philippines, and did not make landfall, respectively. Cyclonic (cross) symbol at the end of each tracks marks the center position on the final PAGASA warning for TCs that exited PAR (weakened into a remnant low within the PAR). (b) The frequency of best track positions with initial intensities under tropical depression (TD; $<18 \mathrm{~m} \mathrm{~s}^{-1}$ ), tropical storm (TS; $18-24 \mathrm{~m} \mathrm{~s}^{-1}$ ), severe tropical storm (STS; $25-32 \mathrm{~m} \mathrm{~s}^{-1}$ ), typhoon (TY; $33-61 \mathrm{~m} \mathrm{~s}^{-1}$ ), and super typhoon (STY 62+ $\mathrm{m} \mathrm{s}^{-1}$ ) categories. (c) The distribution of best track 24-h intensity changes within the PAR. 
winds for the TC cases (Fig. 1c), 53.4\% of the observed 24-h intensity change within the PAR had an increase of at least $1 \mathrm{~m} \mathrm{~s}^{-1}$ while $29.7 \%$ had a decrease of at least $1 \mathrm{~m} \mathrm{~s}^{-1}$, suggesting that most of the 63 cases were in the developing or intensifying stage. Rapid intensification and weakening constitute $4.2 \%$ and $3.1 \%$ of the observed 24 -h intensity changes within the PAR for the 63 cases, respectively. PAGASA track forecasts during the occurrences of these TC cases served as the reference track forecast input to run the WAIP. Because the weighted mean intensity forecast from WAIP is derived from the intensity evolutions of historical analogs from the JTWC best tracks, the output intensity forecast of the model is provided at 1-minute averaging period. Tsai and Elsberry (2014) noted that TC warning centers that use 10-minute averaging period must convert the initial intensity input to 1 -minute averaging and the weighted mean intensity forecast to the 10-minute standard. However, the study did not specify a particular method for doing such conversion. PAGASA meteorologists operationally interconvert wind speed values of different averaging periods by remapping maximum winds to and from its equivalent Dvorak current intensity (CI) number using the lookup tables being used by the agencies in question (Knapp and Kruk 2010; Barcikowska et al. 2012; Mei and Xie 2016). This approach, also known as the "CI number method" assumes that the CI number is an intrinsic parameter of a tropical cyclone and should be the same for any tropical cyclone at any initial time. Under this approach, the 10-minute wind is converted to a CI number using the Koba et al. (1991) (K91) table. The resulting CI number is then converted to its equivalent 1-minute wind using the Dvorak (1984) (D84) table. Table 1 presents the CI number to maximum wind conversion of the K91 and D84 tables. However, such conversion is only applied when the wind speed value is greater than $65 \mathrm{kt}$ and, as such, 10-minute winds from 0 to $65 \mathrm{kt}$ are considered equal in 1-minute averaging. The rationale behind this conditional rule is that when the CI number method is applied as it is, 10-minute winds of 0 to $65 \mathrm{kt}$ will be higher than their corresponding values in 1 -minute averaging. In equation form, the conversion for 1 -minute or 10-minute winds above $65 \mathrm{kt}$ is expressed as

$V_{10}=V_{1} \times 0.5604+27.9627$

$V_{1}=V_{10} \times 1.7827-49.7285$

where $V_{10}$ and $V_{1}$ are 10-minute and 1-minute winds expressed in knots. Following the recommendation by Tsai and Elsberry (2014) to interconvert between wind speeds of different averaging times and to ensure consistency with operational practices at PAGASA, the CI number method with conditional rule was used to convert the initial intensity of the target TC to 1-minute averaging using Eq. (3) and the resulting intensity forecast of WAIP to 10-minute averaging using Eq. (4). This method is referred in this work as the "conditional CI number method".

The TCs that entered the PAR in 2014 had a maximum forecast length of $72 \mathrm{~h}$ while the TCs for 2015 to $2017 \mathrm{had}$ 120 h. Given that PAGASA does not issue track forecasts beyond $120 \mathrm{~h}$, the maximum forecast length generated by WAIP in this work was $120 \mathrm{~h}$. Intensity forecasts were generated by WAIP from the reference track forecasts issued at standard synoptic times (i.e., 00, 06, 12, and 18 UTC) and the forecast values are reported at 12-h intervals up to $48 \mathrm{~h}$ and at 24-h intervals from $48 \mathrm{~h}$ to $120 \mathrm{~h}$. The resulting intensity forecasts were verified against the best track intensities of the state weather bureau. With WAIP requiring a minimum forecast length of $72 \mathrm{~h}$, not all official track forecasts were used as reference track forecast for WAIP because the official track forecasts prior to 2018 were truncated at the first forecast center position located outside the PAR region. WAIP forecast intensities at forecast positions located outside the PAR were not verified because PAGASA best track data were limited within the PAR region only (i.e., best tracks were only extended outside the PAR starting in 2018).

Continuous verification scores were employed to determine the performance of WAIP intensity forecasts at different forecast times. The performance of WAIP at each forecast time was also compared against a reference forecast. In this study, persistence was used where it is assumed that the intensity throughout the entire forecast track remains the same as the initial intensity, hence a no-decision forecast.

Table 1. The conversion of CI number from Dvorak technique to maximum winds in the WNP basin according to Dvorak (1984) and Koba et al. (1991). Wind speed values are in knots.

\begin{tabular}{ccc}
\hline CI & D84 & K91 \\
\hline 1.0 & 25 & 22 \\
1.5 & 25 & 29 \\
2.0 & 30 & 36 \\
2.5 & 35 & 43 \\
3.0 & 45 & 50 \\
3.5 & 55 & 57 \\
4.0 & 65 & 64 \\
4.5 & 77 & 71 \\
5.0 & 90 & 78 \\
5.5 & 102 & 85 \\
6.0 & 115 & 93 \\
6.5 & 127 & 100 \\
7.0 & 140 & 107 \\
7.5 & 155 & 115 \\
8.0 & 170 & 122 \\
\hline
\end{tabular}


Selected TC cases were also presented to demonstrate the limitations of the analog model in providing intensity guidance to forecasters.

\section{RESULTS AND DISCUSSION}

\subsection{Verification for Philippine TCs from 2014 to 2017}

The verification scores are based on the investigation of 629 WAIP runs covering the 63 TC cases. Sample size ranges from 629 at $12 \mathrm{~h}$ to 29 at $120 \mathrm{~h}$. The MAE and mean intensity bias of both WAIP and persistence at each forecast time and the number of samples verified are given in Fig. 2. The MAE of WAIP intensity forecasts was around $2.91 \mathrm{~m} \mathrm{~s}^{-1}$ at $12 \mathrm{~h}$ then gradually increased to around $5.86 \mathrm{~m} \mathrm{~s}^{-1}$ around $36 \mathrm{~h}$. The value gradually plateaued at around $6.4 \mathrm{~m} \mathrm{~s}^{-1}$ at $48 \mathrm{~h}$ to $72 \mathrm{~h}$ before rapidly increasing to $12.52 \mathrm{~m} \mathrm{~s}^{-1}$ at $120 \mathrm{~h}$. The trend up to $72 \mathrm{~h}$ follows similarly to the intensity MAE of Tsai and Elsberry (2014). However, the MAE in the said study plateaued even beyond $72 \mathrm{~h}$ instead of rapidly increasing as observed in this study. The MAE of WAIP was consistently smaller than those of persistence up to $96 \mathrm{~h}$ with the difference increasing from $12 \mathrm{~h}$ to $72 \mathrm{~h}$ then decreasing at $96 \mathrm{~h}$. By $120 \mathrm{~h}$, persistence had slightly smaller MAE than WAIP. The difference in the MAE between WAIP and persistence at 12 to $96 \mathrm{~h}$ were statistically significant at $95 \%$ confidence level according to the Wilcoxon signed-rank test (Wilks 2011). At $24 \mathrm{~h}$, the MAE difference was $3.57 \mathrm{~m} \mathrm{~s}^{-1}$ or roughly a $22.5 \%$ reduction in MAE relative to persistence while at $72 \mathrm{~h}$, a $52.1 \%$ reduction in MAE was observed, equivalent to $9.44 \mathrm{~m} \mathrm{~s}^{-1}$. Using the MAE as score metric, the WAIP demonstrated better skill than persistence up to $96 \mathrm{~h}$ and less skillful at $120 \mathrm{~h}$.

A positive intensity bias was exhibited by WAIP predictions at all forecast times, while a negative bias was observed for persistence for the same TC cases. For the first $72 \mathrm{~h}$ of the intensity forecast, the mean bias of WAIP remained below $1.5 \mathrm{~m} \mathrm{~s}^{-1}$, with values gradually increasing from $0.15 \mathrm{~m} \mathrm{~s}^{-1}$ at $12 \mathrm{~h}$ to $1.43 \mathrm{~m} \mathrm{~s}^{-1}$ at $72 \mathrm{~h}$. However, much like the trend in the MAE, the positive bias rapidly increased to $6.03 \mathrm{~m} \mathrm{~s}^{-1}$ at $120 \mathrm{~h}$. Except at the 120-h mark, the magnitude of bias in WAIP forecasts remained consistently smaller than persistence. However, the observed biases for the samples limited within the PAR region did not follow the findings of Tsai and Elsberry (2014) wherein the forecast biases were less than $0.5 \mathrm{~m} \mathrm{~s}^{-1}$ over most of the forecast times.

The distribution of underestimation and overestimation of actual winds in the WAIP intensity forecasts is presented in Fig. 3. In this study, a WAIP forecast is considered to overestimate (underestimate) best track winds at a particular forecast time if the error is greater than $1 \mathrm{~m} \mathrm{~s}^{-1}$ (less than $-1 \mathrm{~m} \mathrm{~s}^{-1}$ ). Between 12 and $72 \mathrm{~h}$, WAIP exhibited increasing proportions of overestimations and underestimations, although the rate of increase of overestimations was higher, consistent with the observed positive bias of the model at all forecast times. At $12 \mathrm{~h}$, overestimations and underestimations constituted around $36.6 \%$ and $29.9 \%$ of the forecasts, respectively. This proportion increased to $45.1 \%$ for overestimations and $38.5 \%$ for underestimations at $72 \mathrm{~h}$. The proportion of overestimations more than $5 \mathrm{~m} \mathrm{~s}^{-1}$ increased rapidly from $6.0 \%$ of the forecasts at $12 \mathrm{~h}$ to $26.9 \%$ at $36 \mathrm{~h}$ before the trend eases off a bit, reaching $32.4 \%$ at $72 \mathrm{~h}$. In terms of extreme values of forecast biases at each model run, the magnitudes of the maximum overestimations remained much larger than those of overestimations, with values ranging from $15 \mathrm{~m} \mathrm{~s}^{-1}$ at $12 \mathrm{~h}$ to $29 \mathrm{~m} \mathrm{~s}^{-1}$ at $72 \mathrm{~h}$.

At the 96-h and 120-h intervals, the number of overestimations were disproportionate compared to both underestimations and those with forecast biases of at most $1 \mathrm{~m} \mathrm{~s}^{-1}$. Overestimations at these forecast intervals constituted $63.0 \%$ to $65.5 \%$ of the WAIP forecasts while underestimations were only $26.0 \%$ to $27.6 \%$ of the verified runs, respectively. Most of the overestimations at these forecast intervals had magnitudes more than $5 \mathrm{~m} \mathrm{~s}^{-1}$, although the maximum values observed at $96-\mathrm{h}\left(18 \mathrm{~m} \mathrm{~s}^{-1}\right)$ and $120-\mathrm{h}$ periods $\left(23 \mathrm{~m} \mathrm{~s}^{-1}\right)$ were lower than the peak underestimations at the same forecast intervals ( 21 and $24 \mathrm{~m} \mathrm{~s}^{-1}$, respectively).

To examine the range of predictions made by WAIP at various forecast intervals for the 2014 - 2017 TC cases, the range of observed intensities from the PAGASA best track and the verified intensity forecast from WAIP at 36, 72, and $96 \mathrm{~h}$ are presented in Fig. 4 . At $36 \mathrm{~h}$, the $\pm 25 \%$ range about the median (i.e., interquartile range or IQR) TC intensity observed within the PAR is unskewed with an upper value of $42 \mathrm{~m} \mathrm{~s}^{-1}$ and a lower value of $22 \mathrm{~m} \mathrm{~s}^{-1}$. The extreme values at $36 \mathrm{~h}$ range from 13 to $62 \mathrm{~m} \mathrm{~s}^{-1}$ (i.e., super typhoon category of PAGASA). Slightly skewed compared to observed intensities, the WAIP-predicted maximum winds at $36 \mathrm{~h}$ had smaller IQR with an upper value of $42 \mathrm{~m} \mathrm{~s}^{-1}$ and a lower value of $26 \mathrm{~m} \mathrm{~s}^{-1}$. The model was able to predict the lower extreme value of $11 \mathrm{~m} \mathrm{~s}^{-1}$ (i.e., weakening to a remnant low) but the forecast extreme value of $54 \mathrm{~m} \mathrm{~s}^{-1}$ was notably lower than the observed maximum of $62 \mathrm{~m} \mathrm{~s}^{-1}$.

For the observed intensities at $72 \mathrm{~h}$, the IQR was smaller and more skewed compared to $36 \mathrm{~h}$ with upper and lower values at 41 and $23 \mathrm{~m} \mathrm{~s}^{-1}$, respectively. In comparison, the IQR of predicted intensities at $72 \mathrm{~h}$ was considerably smaller and less skewed with a much lower value $\left(29 \mathrm{~m} \mathrm{~s}^{-1}\right)$ and nearly similar upper value $\left(40 \mathrm{~m} \mathrm{~s}^{-1}\right)$. The IQR of WAIP at $72 \mathrm{~h}$ was also smaller and slightly less skewed than the predictions at $36 \mathrm{~h}$. The range of extreme values of predicted intensities was considerably smaller at $72 \mathrm{~h}$ than both the observed intensities at $72 \mathrm{~h}$ and the predictions at $36 \mathrm{~h}$.

The observed intensities at $96 \mathrm{~h}$ had a slightly larger IQR that is less skewed with smaller range of extreme values compared to predictions. However, the WAIP predictions at this forecast interval had a much smaller IQR than the observed intensities with a lower value of $30 \mathrm{~m} \mathrm{~s}^{-1}$, and 

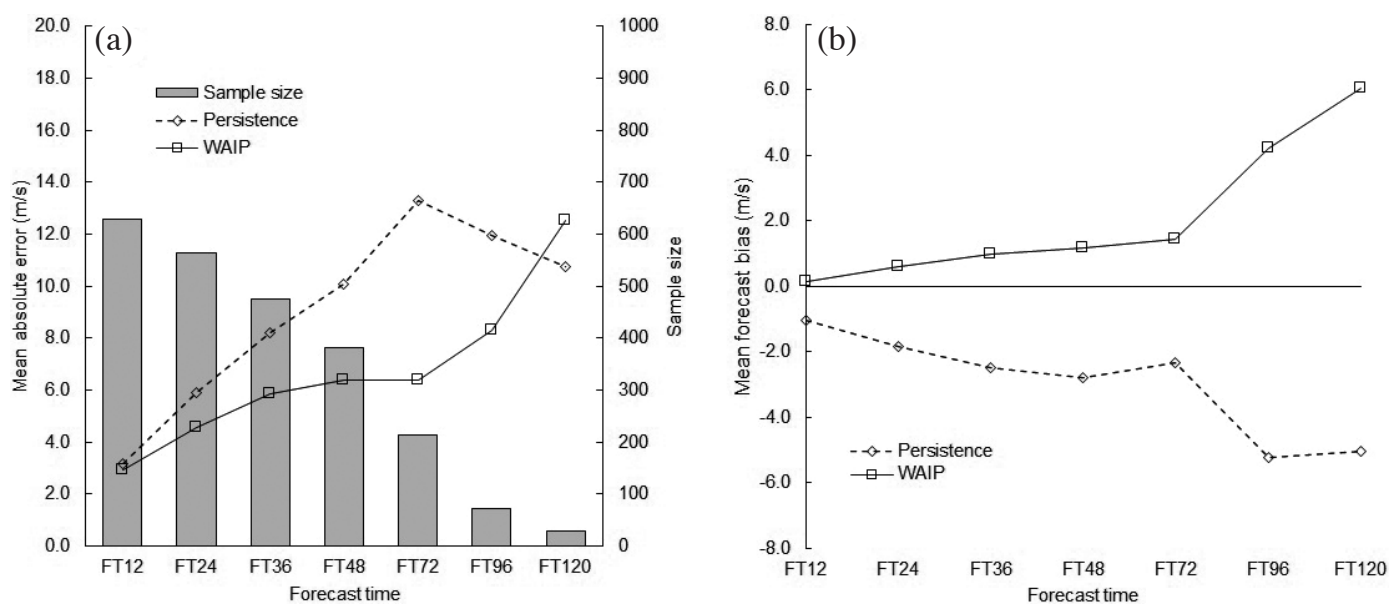

Fig. 2. Homogeneous comparison of WAIP and persistence intensity forecasts for 63 TC cases in the PAR region from 2014 to 2017 : (a) mean absolute errors $\left(\mathrm{m} \mathrm{s}^{-1}\right)$ and (b) mean forecast biases $\left(\mathrm{m} \mathrm{s}^{-1}\right)$ as a function of forecast time (hours). The sample sizes at each forecast time are also presented as a bar graph in panel (a).

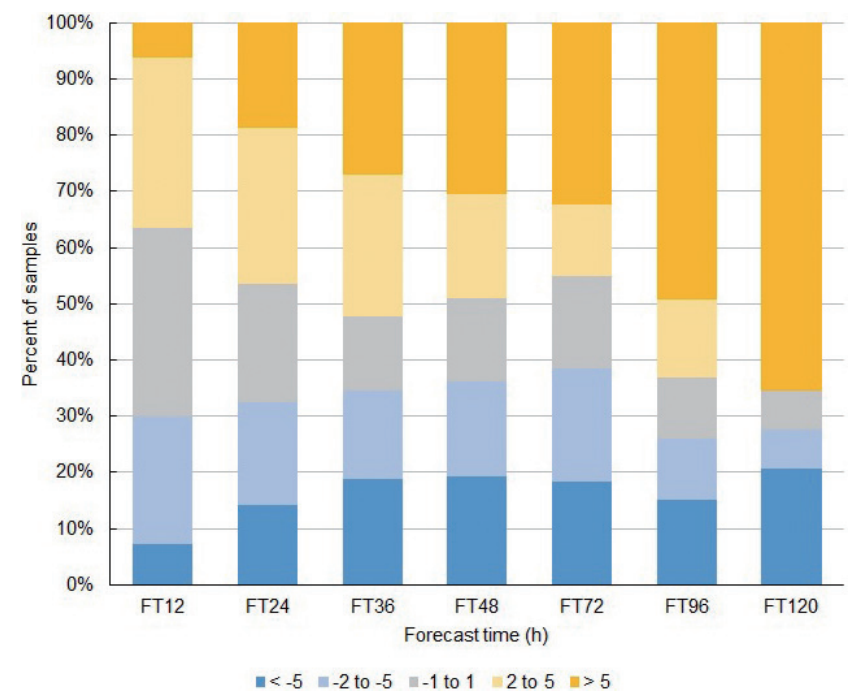

Fig. 3. Number of WAIP forecasts (as percentage of total number of verified runs) with magnitude of intensity bias of at most $1 \mathrm{~m} \mathrm{~s}^{-1}, 2$ to $5 \mathrm{~m} \mathrm{~s}^{-1}$ 6 to $10 \mathrm{~m} \mathrm{~s}^{-1}$, and greater than $10 \mathrm{~m} \mathrm{~s}^{-1}$ at each forecast times. Darker shade of yellow (blue) indicates higher magnitude of intensity overestimation (underestimation) by WAIP. Gray shades are for WAIP forecasts with error of at most $1 \mathrm{~m} \mathrm{~s}^{-1}$.
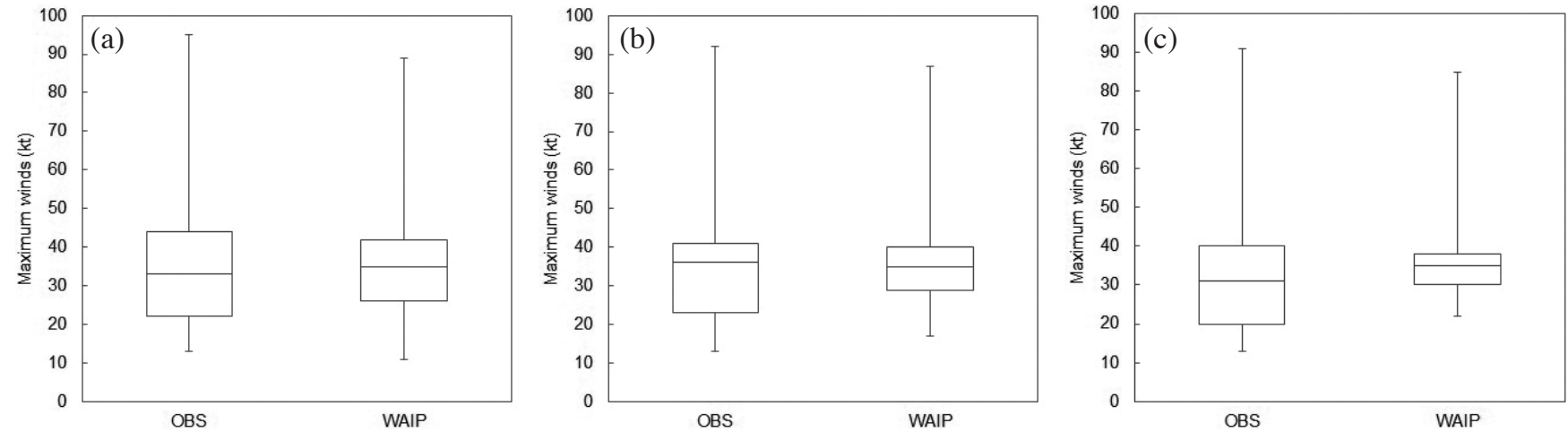

Fig. 4. Box-and-whisker plots for the observed intensities and the intensity forecast from WAIP at (a) $36 \mathrm{~h}$, (b) $72 \mathrm{~h}$, and (c) $96 \mathrm{~h}$ respectively. In these box plots, the horizontal line near the middle of the box represents the median intensity value, the top and bottom of the box are the $3^{\text {rd }}$ and $1^{\mathrm{st}}$ quartile $(75 \%$ and $25 \%)$ intensity values, and the top and bottom flat caps of the vertical lines are the maximum and minimum intensity values. 
an upper value of $38 \mathrm{~m} \mathrm{~s}^{-1}$. This lower value was $1 \mathrm{~m} \mathrm{~s}^{-1}$ lower than the median observed intensity at $96 \mathrm{~h}$. The range of extreme values for the predicted intensities was smaller than the observed intensities, with WAIP having a minimum value of $22 \mathrm{~m} \mathrm{~s}^{-1}$ and a maximum value $49 \mathrm{~m} \mathrm{~s}^{-1}$. While the upper extreme value of predicted intensities was near to that of observed intensities at $96 \mathrm{~h}$ (albeit smaller by $2 \mathrm{~m} \mathrm{~s}^{-1}$ ), the lower extreme value of the predicted intensities was much higher than the observed intensities.

While the verification scores demonstrated the skill of WAIP relative to persistence in providing baseline intensity prediction for the PAR region at the 12-h to 96-h intervals, the range of predicted intensities by WAIP at $96 \mathrm{~h}$ does not capture the observed intensities at the same forecast interval, with the model struggling to predict lower range of intensity values. This, along with the trend in the MAE beyond $72 \mathrm{~h}$ that is contrary to those observed by Tsai and Elsberry (2014), implies that the WAIP may be of potential use as baseline intensity forecast at the 12-h to 72-h range for the PAR region. The forecast performance of WAIP at the 96-h and 120-h was a noteworthy departure from the findings of Tsai and Elsberry (2014). However, at these forecast intervals, the study had small sample size with only 73 and 29 forecast intensities at 96 and $120 \mathrm{~h}$ verified against PAGASA best track compared to 213 at $72 \mathrm{~h}$. The truncation in the reference forecast track and best track data of PAGASA within the PAR region until 2017 and the absence of 5-day track forecast in 2014 and some of 2015 TC cases resulted in limited number of 96-h and 120-h WAIP forecasts that can be verified against the PAGASA best track.

Although verification results were promising at the 12-h to 72-h periods, Fig. 4 showed that the full range of the observed intensities of the extreme values may not be captured well by the model especially at higher forecast times, which is expected in a statistical model. Sections 3.2 to 3.4 feature selected TC events which discuss some important points of the intensity forecasts from WAIP which can be critical in its operational use. A discussion of the potential source of the observed positive intensity bias is presented in section 3.5 .

\subsection{Availability of Historical Analogs: Typhoon Maysak}

As the third TC to enter the PAR in 2015, Typhoon Maysak originated from an area of low pressure first noted as a tropical depression over the sea east of Pohnpei, Micronesia at 12 UTC of 26 March 2015. Following a westnorthwestward heading, Maysak reached typhoon category within 3 days of genesis around Chuuk, Micronesia (Japan Meteorological Agency 2016). Shortly past 15 UTC on 1 April, Maysak entered the PAR with maximum winds of $50 \mathrm{~m} \mathrm{~s}^{-1}$ and was assigned the domestic name "Chedeng". Figure 5a presents the observed track and category of Maysak at 6-h intervals within the PAR region. As it continued moving west northwestward towards the northern portion of Luzon island, Maysak encountered unfavorable environment, causing it to rapidly weaken to a tropical depression before making landfall in the province of Isabela at around 00 UTC on 5 April. It was last tracked as a remnant low over the Cordillera Central mountain range at 06 UTC of the same day.

Figure $5 \mathrm{~b}$ shows the WAIP intensity forecasts initialized at 12-h intervals from 12 UTC 01 April to 12 UTC 03 April and the PAGASA observed intensities from 12 UTC
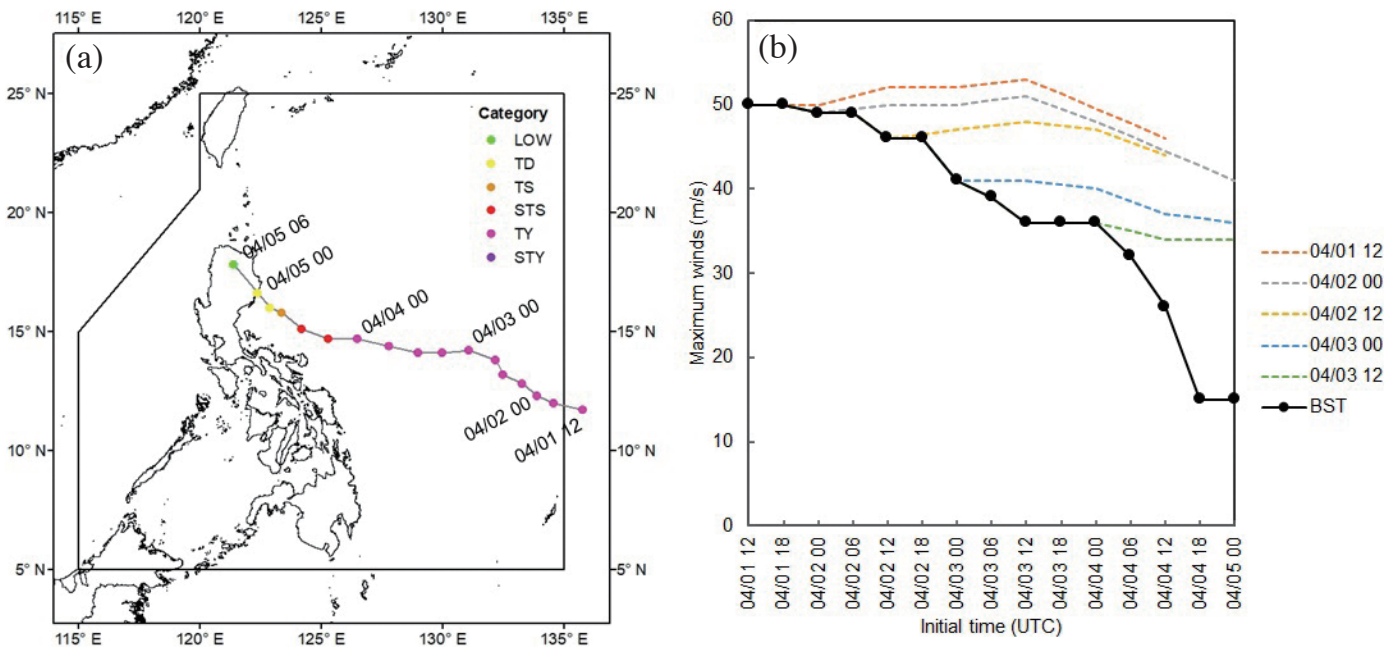

Fig. 5. (a) PAGASA six-hourly observed track of Typhoon Maysak. The colors in each center position indicates the category of the tropical cyclone (i.e., LOW: low pressure area, TD: tropical depression, TS: tropical storm, STS: severe tropical storm, TY: typhoon, STY: super typhoon). (b) WAIP intensity forecast from 12 UTC 01 April to 12 UTC 03 April (colored dashed lines) and the PAGASA observed intensities at 6-h intervals (solid black line with filled circle markers). The forecasts presented in the figure were those initialized at 00 and 12 UTC. Maximum winds presented in the chart use 1-minute averaging. 
on 1 April to 00 UTC of 5 April. The weakening phase of Maysak from the time it entered the PAR until its landfall and demise over northern Luzon was not captured in both magnitude and timing by any of the forecast runs. All WAIP runs predicted that Maysak will either slightly intensify and reach peak strength at 12 UTC on 03 April before weakening (for 01 to 02 April runs) or briefly maintain strength then slightly weaken without seeing a period of intensification (for 03 April runs). For all runs, WAIP did not predict that Maysak will rapidly weaken into a tropical depression prior to landfall and into a remnant low over Luzon.

Figure 6 presents the historical analogs and the corresponding intensity evolutions that were used in each of the 5 intensity forecasts presented in Fig. $5 \mathrm{~b}$ alongside the reference track forecast of WAIP and the corresponding WAIP intensity forecast. The mean $d_{T}$ of the historical analogs used in all WAIP forecasts for Maysak was $5.06^{\circ}$ or roughly $562 \mathrm{~km}$. Of all the analogs used in the forecast runs, less than half resembled the reference track forecast. The degree of spread of the analogs worsened in the later runs, with $d_{T}$ reaching a maximum value of $7.1^{\circ}$. While the later runs presented intensity evolutions that showed rapid weakening, these did not reflect in the final WAIP forecast because nearly all these evolutions were associated with historical analogs having either west-northwestward-oriented tracks that are landfalling over Visayas-Mindanao area or recurving track over the Philippine Sea far off the coast of Luzon. Only one of the analogs that showed significant weakening was oriented in the same way as the reference track forecast for Maysak but instead of proceeding with a northern Luzon landfall, the analog moved slowly with its track stalling over the sea east of northern Luzon.

This case highlights that while the accuracy of the reference track forecast may not be an issue, the quality of the intensity forecast generated by WAIP is highly dependent on the number of available historical analogs in a particular region for a certain period of the year (i.e., for WAIP, within \pm 30 days of the initial time of the reference track forecast) and the degree of resemblance of these analogs to the reference track forecast. In the case of Maysak, PAGASA generally captured its heading and translation speed. In particular, the mean forecast error of the reference track forecasts used by WAIP was $100.4,156.6$, and $111.0 \mathrm{~km}$ for 24,48 , and $72 \mathrm{~h}$, respectively. Figure 6 suggests that the number of historical analogs of Maysak having a similar track orientation during that time of the year may be limited because many of the analogs that were eventually used barely resembled its west-northwestward heading towards northern Luzon.

\subsection{Effect of Reference Track Forecast Accuracy: Typhoon Talim}

Typhoon Talim was first noted as a tropical depression over the sea northeast of Guam around 12 UTC on
8 September 2017 (Japan Meteorological Agency 2018). Following a west-northwestward direction, it entered the PAR as a typhoon with domestic name "Lannie" with maximum winds of $33 \mathrm{~m} \mathrm{~s}^{-1}$ around 06 UTC on 11 September. Figure 7a presents the observed track and category of Talim at 6-h intervals within the PAR region. While remaining at sea inside the PAR, Talim slightly decelerated without significant change in direction for the next $48 \mathrm{~h}$. After maintaining its west-northwestward direction, over the northern portion of the Philippine Sea, Talim left the PAR with maximum winds of $36 \mathrm{~m} \mathrm{~s}^{-1}$ at 06 UTC on 13 September towards the Ryukyu Islands. While over the East China Sea, Talim slowed down as it recurved towards Japan. Now following a northeastward direction, Talim crossed Japan as a severe tropical storm on 17 September. It eventually transitioned into an extratropical cyclone at 18 UTC of the same day as it moved off the coast of Honshu towards the Sea of Japan (Japan Meteorological Agency 2018).

Figure $7 \mathrm{~b}$ shows the intensity forecasts from WAIP with initial times at 06 and 18 UTC of 11 to 12 September and the PAGASA observed intensities from 06 UTC 11 September to 06 UTC 13 September. Over the 48-h period the typhoon was inside the PAR, its intensity only increased by $3 \mathrm{~m} \mathrm{~s}^{-1}$. In the forecast run at 06 UTC of 11 September, WAIP predicted steady intensification, with maximum winds reaching a peak of $43 \mathrm{~m} \mathrm{~s}^{-1}$ by 18 UTC of 12 September. Figure 8 shows that PAGASA initially predicted Talim to follow a west-northwestward track bringing it to a landfall in northern Taiwan. For this run, the historical analogs selected by WAIP had a tight clustering with $d_{T}$ of $2.3^{\circ}$ or roughly $256 \mathrm{~km}$. Figure 9 shows that the selected analogs presented a steady intensification up to the 48 -h to $60-\mathrm{h}$ period followed by a steady weakening associated with each analog's landfall over Taiwan and mainland China.

The case of Typhoon Talim emphasizes that the representativeness of the historical analogs and the resulting intensity forecast of WAIP heavily relies on the accurate prediction of the track forecast scenario. The observed track of the typhoon (Fig. 7a) did not make landfall over northern Taiwan unlike what was earlier predicted. In particular, the track forecast verification (Table 2) revealed that at all forecast times, all reference track forecasts of Talim had larger errors in the cross-track component than in the along-track component. This meant that the reference track forecasts for Talim failed to capture where the typhoon will be heading more than how fast the typhoon will be moving due to failure in initially capturing the recurving scenario in the forecast tracks.

Figure 8 shows that PAGASA forecasters gradually shifted the official track forecast to a west-northwestward turning northwestward path towards the Ryukyu Islands followed by a recurvature to the northeast while over the East China Sea once the track forecast guidance slowly converged to a no-landfall scenario in the succeeding runs. The 

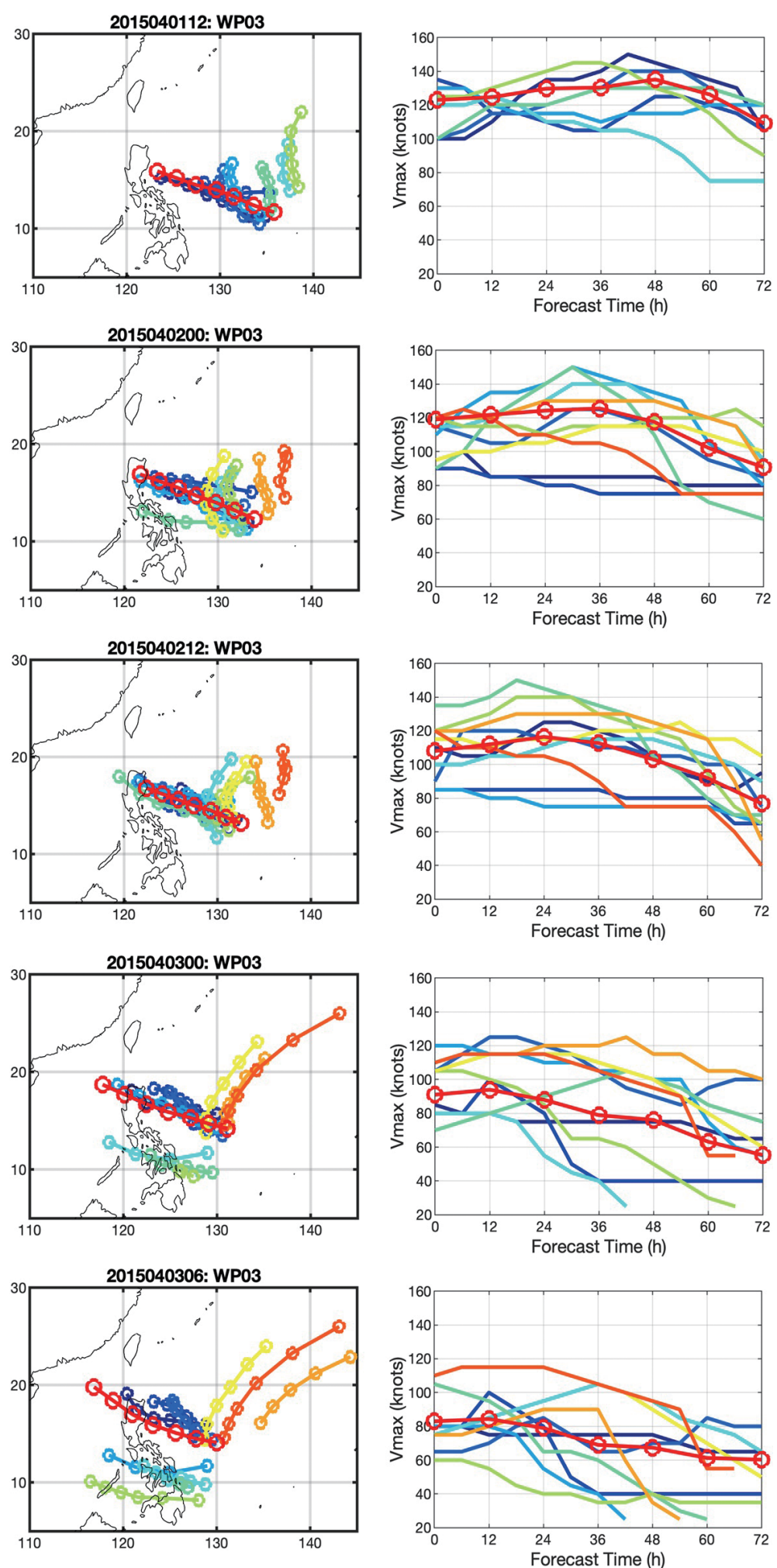

Fig. 6. Tracks of the historical analogs from the JTWC best track database that were used in the WAIP intensity forecasts from 12 UTC 01 April to 12 UTC 03 April (left) and the intensity evolution of these analogs (right). The red lines and markers in each figure panel indicate the reference track forecast (left) and the resulting WAIP intensity forecast (right). Each analog is differentiated by color. 

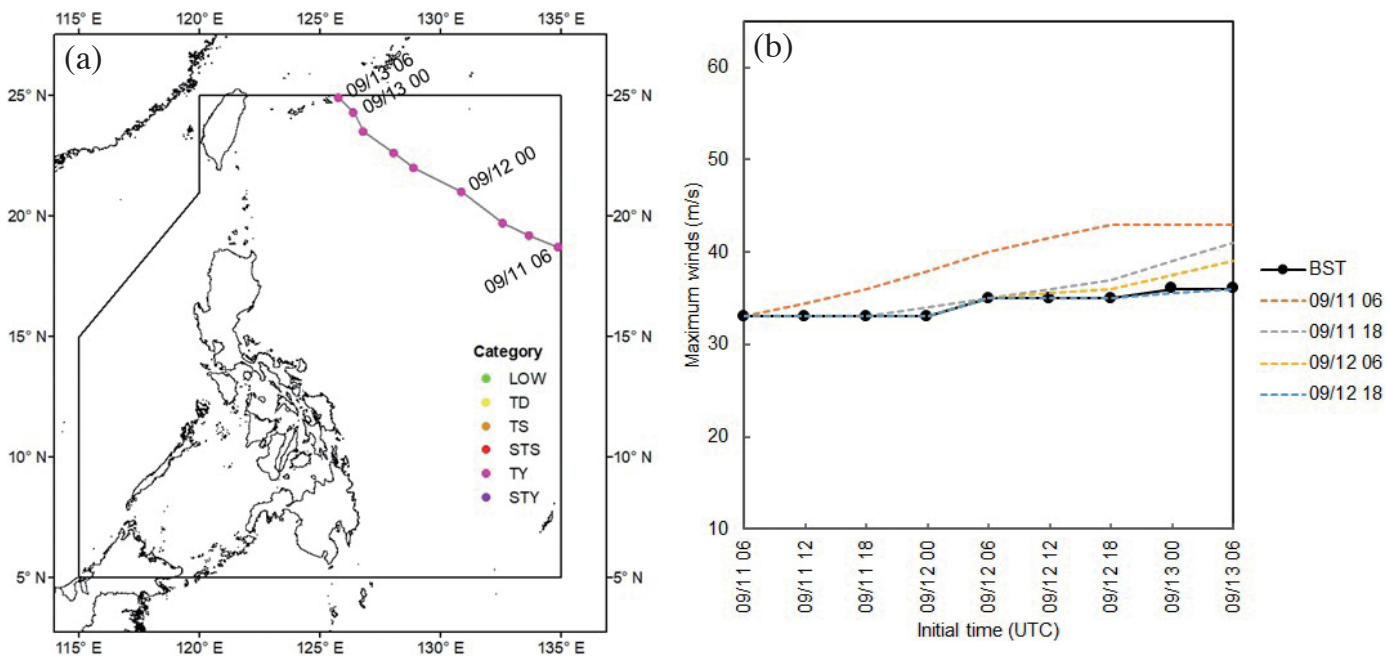

Fig. 7. Same as Fig. 5, except that (a) is for Typhoon Talim and (b) is for the WAIP forecasts at 06 and 18 UTC of 11 to 12 September.

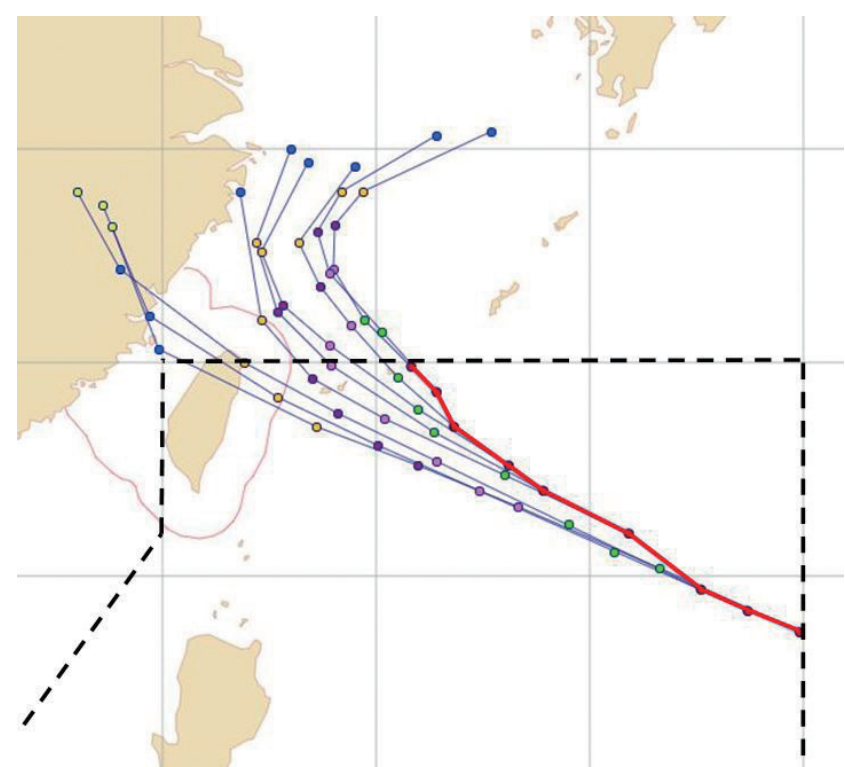

Fig. 8. PAGASA best track (red solid line) and official track forecasts for Typhoon Talim. The best track positions are at 6-h intervals, while the forecast positions are available at 12-h intervals up to $48 \mathrm{~h}$ (green, pink, purple and yellow markers), and at 24 -h intervals from 72 to $120 \mathrm{~h}$ (blue and green markers). Both the best track and official track forecasts are truncated within the PAR region, whose limits are marked by black dashed line on the map. 

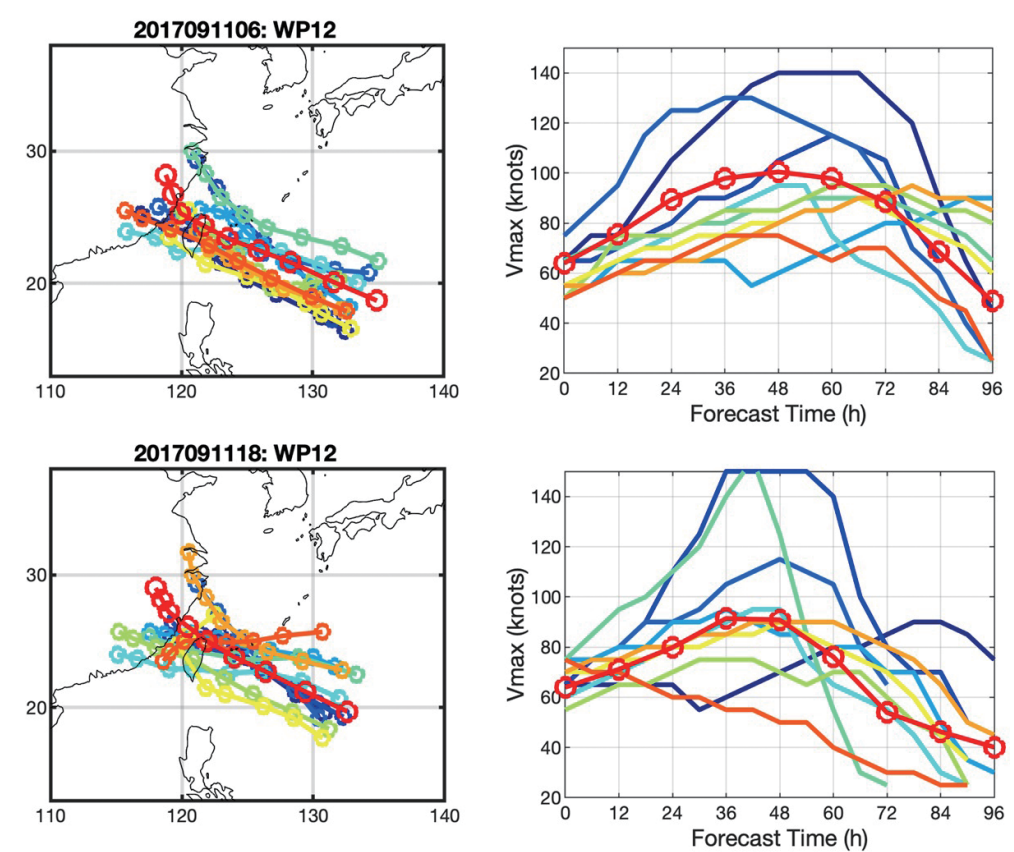

2017091206: WP12
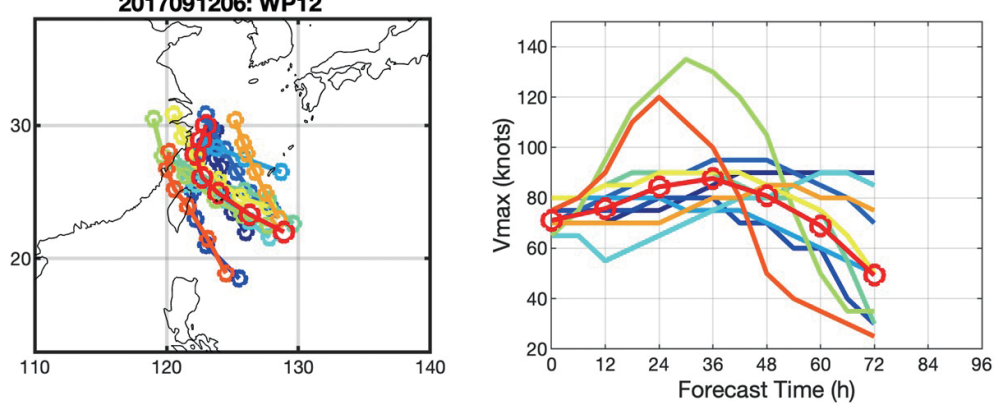

2017091218: WP12
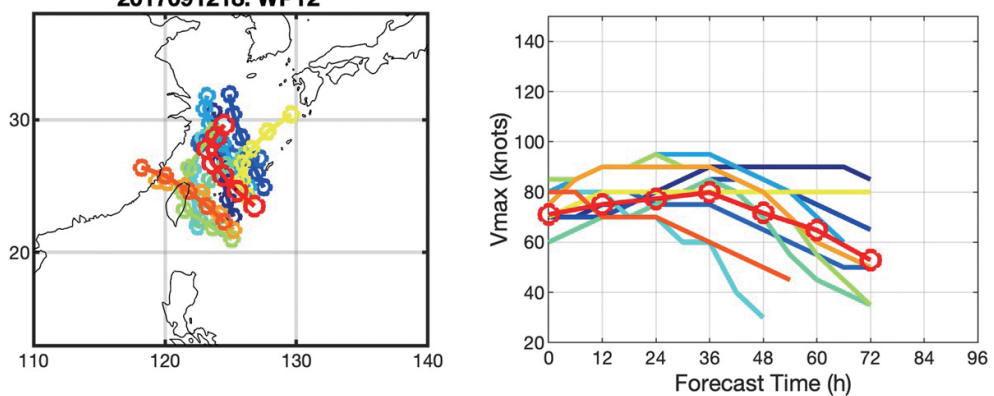

Fig. 9. Same as Fig. 6, but for WAIP forecast runs at 06 and 18 UTC of 11 to 12 September.

Table 2. Average forecast track error and errors along the along-track and cross-track components $(\mathrm{km})$ of PAGASA forecast tracks for Typhoon Talim from 06 UTC 11 September 2020 to 06 UTC 13 September 2020.

\begin{tabular}{cccc}
\hline Forecast Time (h) & Forecast Track Error & Along-Track Error & Cross-Track Error \\
\hline 12 & 66.0 & 37.6 & 40.3 \\
24 & 118.8 & 45.2 & 104.2 \\
36 & 180.3 & 34.0 & 117.3 \\
48 & 274.0 & 40.0 & 270.0 \\
\hline
\end{tabular}


shift in the reference track forecast resulted in an increase in the spread of the historical analogs being chosen by WAIP (Fig. 9) with $d_{T}$ increasing from $2.0^{\circ}$ at 00 UTC of 12 September to $2.9^{\circ}$ at 06 UTC on 13 September. Despite this, Fig. 9 shows that the new analogs in the succeeding WAIP forecasts presented intensity evolutions that were either minimally intensifying, steady state, weakening or a combination of these. These resulted in a notable reduction in intensification rate in the intensity forecasts of succeeding WAIP run which better reflected the minimal change in intensity of Talim observed during the period it was inside the PAR. For instance, the verification revealed that the intensity forecast errors at $12 \mathrm{~h}$ and $24 \mathrm{~h}$ were 3 and $5 \mathrm{~m} \mathrm{~s}^{-1}$, respectively, for the 06 UTC run on 11 September. Twenty-four hours later, the 12-h and 24-h intensity error of the WAIP forecast decreased to 1 and $3 \mathrm{~m} \mathrm{~s}^{-1}$, respectively.

\subsection{Capturing Unusual TC Cases: Typhoon Tembin}

Figure 10a presents the six-hourly observed positions of Typhoon Tembin within the PAR region. The last TC of the 2017 season was first noted as a tropical depression with domestic name "Vinta" at 06 UTC of 20 December 2017 while situated near Palau. Tracking generally westward, Tembin intensified into a tropical storm within $12 \mathrm{~h}$ of formation and into a severe tropical storm $6 \mathrm{~h}$ before making landfall over the southeastern portion of Mindanao island at 18 UTC on 21 December. Owing to frictional effects, the system weakened into a tropical depression while crossing the island although it quickly reorganized after emerging over the Sulu Sea on 22 December. Favorable conditions resulted to Tembin rapidly intensifying into a typhoon just after passing over the southern tip of Balabac Island between Palawan and Borneo. At 00 UTC on 24 December, Talim left the PAR towards the direction of southern Vietnam. By 12 UTC of the same day, Tembin began to rapidly weaken and at 12 UTC on 25 December, it was downgraded into a tropical depression while off the southern coast of Vietnam. Tembin was last tracked on 26 December while over the Gulf of Thailand to the south of Cambodia (Japan Meteorological Agency 2018).

Figure 10b shows the intensity forecasts from WAIP with initial times at 06 and 18 UTC of 20 and 21 December and at 06 UTC of 22 December as well as the PAGASA observed intensities from 06 UTC 20 December to 00 UTC 24 December. Best track revealed that the typhoon had a peak intensification of $11 \mathrm{~m} \mathrm{~s}^{-1}$ over a 24 -h period prior to landfall, reaching its first peak intensity of $26 \mathrm{~m} \mathrm{~s}^{-1}$ at 12 UTC on 21 December. This was followed by a peak land-driven weakening of $9 \mathrm{~m} \mathrm{~s}^{-1}$ within $24 \mathrm{~h}$, with the intensity dropping to 17 $\mathrm{m} \mathrm{s}^{-1}$ within $12 \mathrm{~h}$ of landfall. Over the Sulu Sea, Tembin underwent a near-rapid intensification of $13 \mathrm{~m} \mathrm{~s}^{-1}$ within $24 \mathrm{~h}$, reaching $33 \mathrm{~m} \mathrm{~s}^{-1}$ at 18 UTC on 23 December. The WAIP forecasts for Tembin that were initialized prior to landfall in Mindanao predicted a steady intensification with maximum winds peaking around 23 to $27 \mathrm{~m} \mathrm{~s}^{-1}$ before landfall, followed by a slowly weakening trend as it crosses Mindanao and the Sulu Sea. Meanwhile, the WAIP forecasts that were initialized at 18 UTC on 21 December or just before the TC emerged over the Sulu Sea predicted that Tembin would remain as a minimal tropical storm until it leaves the PAR region. In both pre- and post-landfall runs, WAIP did not predict any significant period of intensification once Tembin reached the Sulu Sea. While the pre-landfall intensification was slightly captured by WAIP, verification revealed that the model did not capture the degree of subsequent weakening during its land crossing in Mindanao and the rapid intensification to typhoon category over the Sulu Sea.
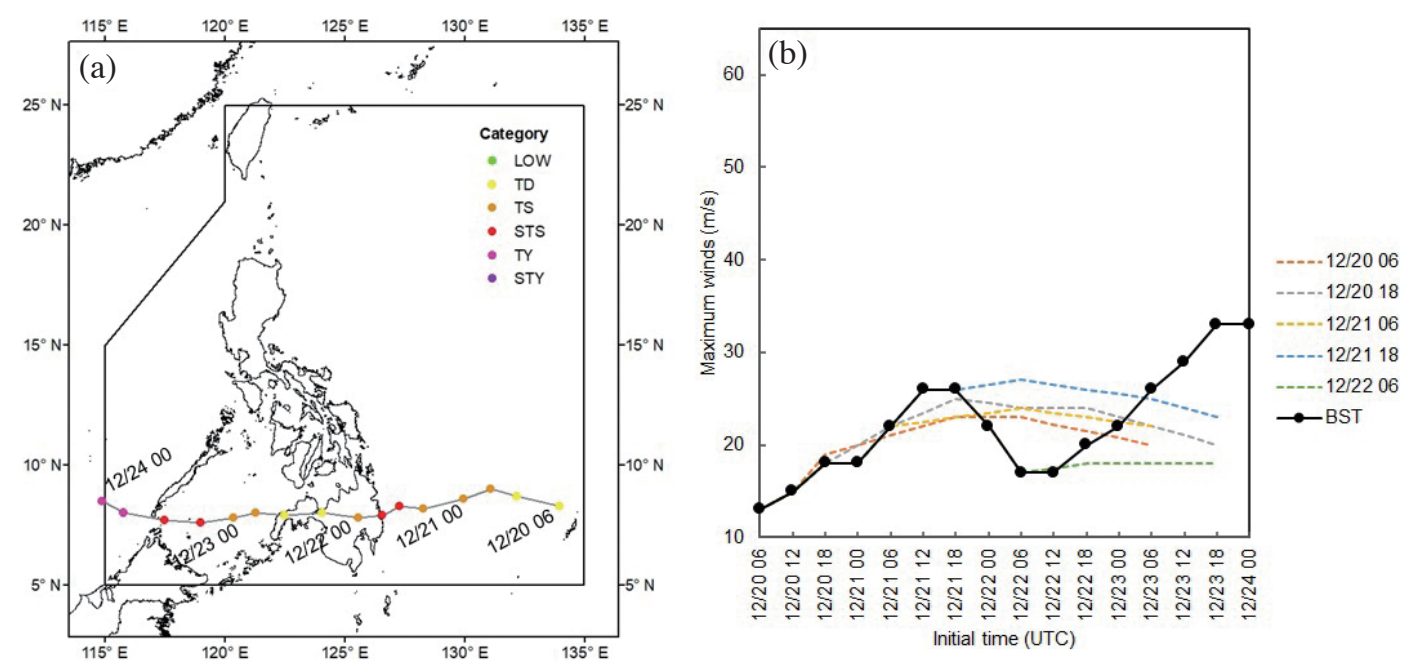

Fig. 10. Same as Fig. 5, except that (a) is for Typhoon Tembin and (b) is for the WAIP forecasts at 06 and 18 UTC of 20 to 21 December and at 06 UTC of 22 December. 
Historical analogs used by WAIP (Fig. 11) show that the mean $d_{T}$ between the analogs and the reference track forecast ranges from 2.7 to $3.4^{\circ}$ (roughly 322 to $378 \mathrm{~km}$ ) for all the forecast runs. Roughly two to four of these analogs were westward-moving that crossed Mindanao and the southern portion of Palawan island having either a period of pre-landfall intensification followed by a continuous weakening during land-crossing over Mindanao and Sulu Sea or a tropical depression or minimal tropical storm with steady state or weakening trend. The rest of the analogs generally moved westward and crossed the archipelago at a much higher latitude (i.e., in Visayas or southern portion of Lu- zon). The presence of the non-Mindanao-crossing analogs and their higher intensity values in their best tracks offset the intensity contributions of the Mindanao-crossing analogs and dampened the rate of weakening over Mindanao in the intensity forecast of WAIP for Tembin.

As for the rapid intensification to typhoon category from tropical depression stage over the Sulu Sea region, WAIP failed to capture this event due to lack of any historical analog that moved generally westward from Mindanao towards southern Palawan that either reached typhoon category or underwent rapid intensification over the Sulu Sea. In particular, the comprehensive best track dataset from the
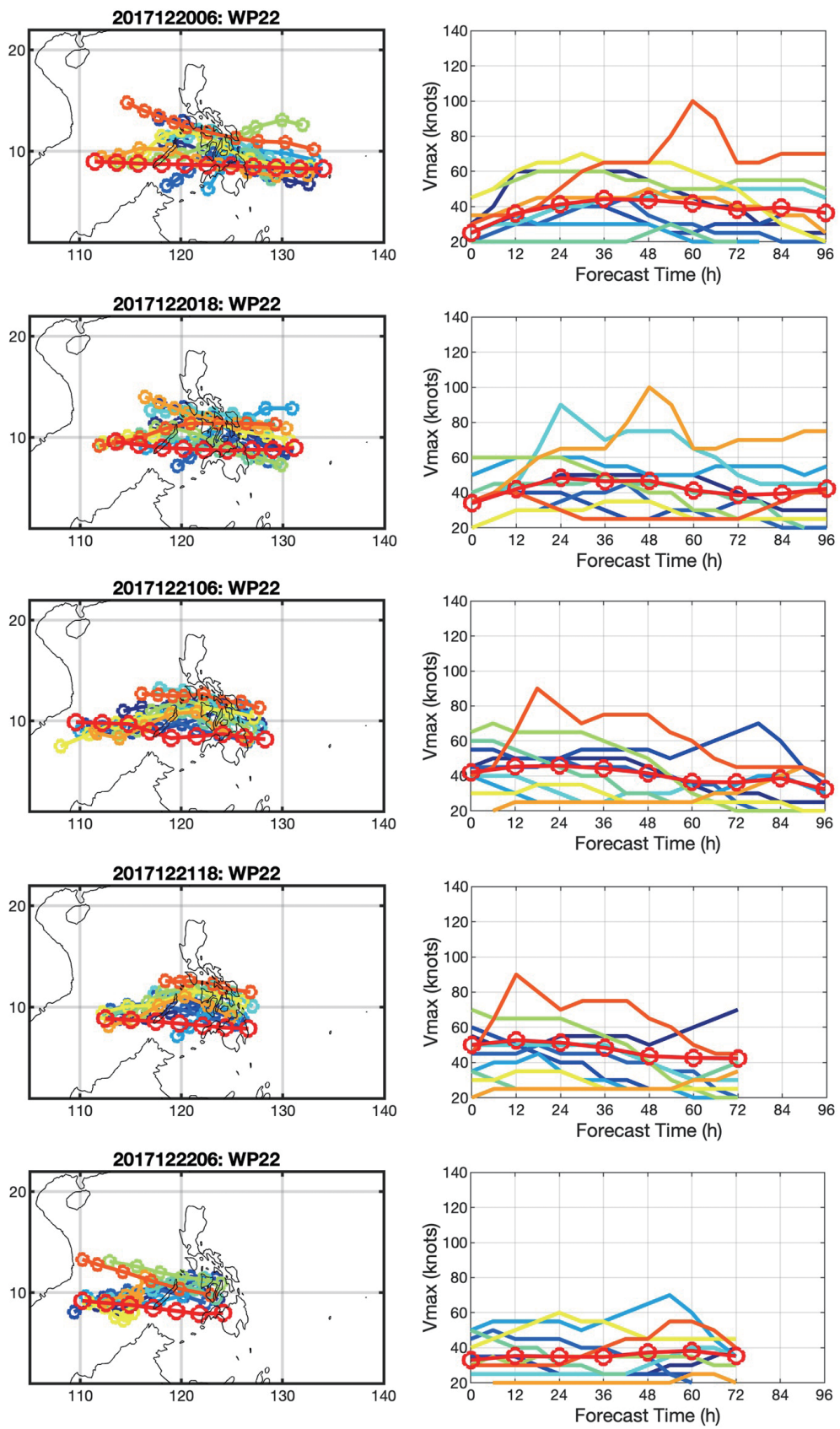

Fig. 11. Same as Fig. 6, but for WAIP forecast runs at 06 and 18 UTC of 20 to 21 December and at 06 UTC of 22 December. 
WMO Regional Specialized Meteorological Center - Tokyo Typhoon Center (RSMC Tokyo) from 1907 to 2017 shows that of the five TCs of at least tropical storm category that crossed within $150 \mathrm{~km}$ of Balabac Island in southern Palawan $\left(8.0^{\circ} \mathrm{N}, 117.0^{\circ} \mathrm{E}\right)$, only 2 TCs followed a generally westward track from Mindanao with Tembin being the only one that reached typhoon category (Fig. 12). PAGASA (2019) eventually noted that Tembin was the only TC in its climatological records to significantly intensify and reach typhoon category over the Sulu Sea, especially in the region south of $10^{\circ} \mathrm{N}$.

The relatively poor performance of WAIP in forecasting the intensity of TCs for tracks located south of $10^{\circ} \mathrm{N}$ was also identified in earlier investigations. For instance, at $72 \mathrm{~h}$, the SDIP method resulted in degradation in intensity forecast by 2.6 to $5.1 \mathrm{~m} \mathrm{~s}^{-1}$ relative to a statistical 5-day intensity forecast from climatology and persistence (ST5D; Knaff et al. 2003) over the region between $0-10^{\circ} \mathrm{N}$ and 120 $-130^{\circ} \mathrm{E}$ (Elsberry and Tsai 2014). Meanwhile, the revisions from SDIP to WAIP degraded the intensity forecast relative to SDIP by 1.5 to $2.3 \mathrm{~m} \mathrm{~s}^{-1}$ over the region between $0-10^{\circ} \mathrm{N}$ and $120-140^{\circ} \mathrm{E}$ (Tsai and Elsberry 2014).

\subsection{The Role of Remapping Wind Speeds of Varying Wind Averaging Periods in the Forecast of WAIP}

It has been emphasized earlier that the five-day and seven-day versions of the WAIP for WNP TCs utilized the JTWC best track files to determine the candidate analogs to be used in calculating the weighted mean intensity forecast of the model (Tsai and Elsberry 2014). JTWC reports the maximum winds of TCs in its best track record in terms of 1-minute averaging period (Knapp and Kruk 2010). This is different from the 10-minute averaging period prescribed by the WMO that is being used by nearly all TC warning centers in the WNP basin, including both the RSMC Tokyo and PAGASA. While Tsai and Elsberry (2014) recommended the conversion of the WAIP inputs from and outputs to the WMO standard of 10-minute averaging, the study did not specify a particular method for doing such conversion.

It has been noted earlier that this study adopted the operational method used by PAGASA meteorologists to interconvert wind speed between 10-minute and 1-minute averaging periods. Called the "conditional current intensity (CI) number method", this approach utilizes the assumption that maximum winds of a TC in both real-time and best track analyses, regardless of wind averaging times, is associated with a particular CI number from the Dvorak (1984) technique. Given that the CI number in the Dvorak method relies on the presentation of a tropical cyclone in satellite imagery at a specific time, in theory, a TC must have the same $\mathrm{CI}$ number regardless of its equivalent maximum winds in any averaging periods. The method of interconversion is discussed in detail in section 2 .

Another approach to interconverting wind speed estimates of varying wind averaging periods is the use of a constant multiplier. Prior to the release of the WMO Guidelines for Converting Between Various Wind Averaging Periods

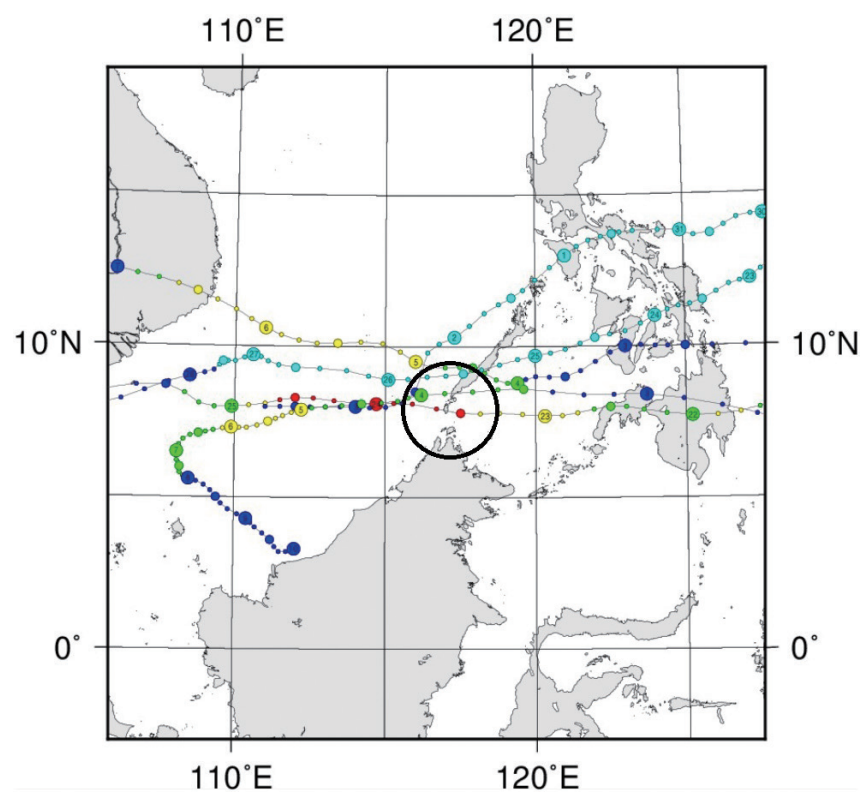

Fig. 12. The best track of five tropical cyclones between 1907 and 2017 (5923 Harriet, 6826 Nina, 8830 Tess, 1301 Sonamu, and 1727 Tembin) that passed within $150 \mathrm{~km}$ from Balabac Island in southern Palawan. The extent of the buffer region is marked by the black circle. The best track positions from RSMC Tokyo are provided at 6-h intervals interpolated to 3-h intervals. The color in each best track position indicates the category of the TC (blue - tropical depression cyan - tropical storm or higher; green - tropical storm; yellow - severe tropical storm; red - typhoon). Map generated from the Digital Typhoon Database of the Japan National Institute of Informatics (http://agora.ex.nii.ac.jp/digital-typhoon/search place.html.en). 
in Tropical Cyclone Conditions (Harper et al. 2010), the examination of many recorded wind speeds against time traces and damage reports brought several conversion factors that can be used from one averaging time to another (i.e., Simiu and Scanlan 1978; Krayer and Marshall 1992). For JTWC interests, the factor 0.88 was used for converting 1-minute to 10 -minute winds while 1.14 was used for converting 10-minute to 1-minute winds (Sampson et al. 1995). Under the WMO report (Harper et al. 2010), four conversion factors were recommended to convert 1-minute winds to 10-minute winds depending on the exposure at near-surface level. In the WNP, the Hong Kong Observatory (HKO) has adopted 0.93 as the nominal conversion factor for all types of exposure (Velden et al. 2012; Burton and Velden 2016; World Meteorological Organization 2020).

To better understand the rationale in not using the recommendation from WMO for remapping between 1-minute and 10-minute winds, one must appreciate the need to reconcile discrepancy in wind estimates in the WNP basin caused by using multiple lookup tables to convert intrinsic metrics of a TC into "measurable" values such as maximum winds and why the use of a constant metric may not be the best solution at hand.

In the absence of aircraft reconnaissance in the WNP basin, operational forecasters perform a quasi-objective analysis of the presentation of TC on either or both visible and infrared imageries to estimate maximum winds of a TC (Dvorak 1984; Velden et al. 2006). Such analysis leads to the determination of a CI number that can take a value between 1.0 to 8.0, with intervals of 0.5. Lookup tables (Dvorak 1984; Koba et al. 1991) provide a mapping from the CI number to the estimated maximum winds of a TC. The D84 lookup table (Dvorak 1984) allows JTWC forecasters to convert CI numbers to maximum wind estimates at 1-minute averaging from $25 \mathrm{kt}$ (for CI 1.0) to $170 \mathrm{kt}$ (for CI 8.0). For agencies in the WNP that use 10-minute averaging, two existing methods are operationally used. The RSMC Tokyo converts CI number to maximum winds using an entirely different table from Dvorak (1984). The table is based on a separate verification using RSMC Tokyo best track data and reanalyzed CI numbers covering a six-year period in the 1980s when aircraft reconnaissance was still being flown by the United States in the WNP. Based on this verification, Koba et al. (1991) introduced the K91 table with maximum wind estimates ranging from $22 \mathrm{kt}$ (for CI 1.0) to 122 $\mathrm{kt}$ (for CI 8.0). Table 1 shows that the K91 relationship is similar to the D84 at the middle of the intensity range, but it assigns significantly higher (lower) wind speeds at low (high) CI numbers. This lookup table is also used by nearly all TC warning centers within the Typhoon Committee region (Velden et al. 2012; Burton and Velden 2016; World Meteorological Organization 2020). In other agencies using 10-minute wind averaging but do not subscribe to the K91 table such as the Hong Kong Observatory (HKO), the CI numbers from the Dvorak analysis are converted to 1-minute winds using the D84 table. The resulting values are remapped to their equivalent maximum winds at 10-minute averaging using the nominal multiplier 0.93 (Burton and Velden 2016). This approach yields a range of wind speed estimation from $23 \mathrm{kt}$ (for CI 1.0) to $158 \mathrm{kt}$ (for CI 8.0).

The presence of three operational lookup tables for two different averaging periods has resulted in discrepancies in maximum wind estimates of WNP TCs, both in best tracks and in real-time analyses (Knapp and Kruk 2010; Barcikowska et al. 2012). Figure 13 presents the maximum wind speed estimates for Typhoon Meranti from 00 UTC 11 September 2016 to 06 UTC 14 September. As the typhoon rapidly intensified, the disparity between agency intensity estimates grew larger. Of the three other intensity estimates presented in Fig. 12, JMA had the nearest values to PAGASA estimates with JMA being $10 \mathrm{kt}$ lower to $5 \mathrm{kt}$ higher than PAGASA. JTWC had disproportionately high intensity estimates for Meranti during the period. Compared to PAGASA estimates, JTWC 1-minute winds were anywhere between 5 and $50 \mathrm{kt}$ higher. Even if JTWC estimates were converted to 10 -minute winds following the WMO-recommended factor, the values were still up to $40 \mathrm{kt}$ higher. Unlike JMA, the estimates from the HKO were higher by as much as $20 \mathrm{kt}$ than PAGASA despite using the same wind averaging period. This can be attributed to the use of D84 lookup table to translate Dvorak-related metrics to 1-minute winds and converting the values to 10-minute winds using the conversion factor. Conversely, when the same conversion factor was used to convert PAGASA, RSMC Tokyo, and HKO 10-minute winds to their 1-minute equivalent, the resulting values were still lower than JTWC 1 -minute winds by up to $40 \mathrm{kt}$ for PAGASA and RSMC Tokyo and up to $25 \mathrm{kt}$ for HKO. Figure 13 shows that the use of a constant multiplier to interconvert between wind speed values of different averaging times may not be enough to close the discrepancy.

In the same figure, however, when JTWC 1-minute winds are converted to 10-minute values using the conditional CI number method, the difference between the resulting JTWC 10-minute winds and the PAGASA 10-minute winds for Meranti is reduced considerably, with the JTWC converted winds being anywhere between $5 \mathrm{kt}$ lower and 10 kt higher than PAGASA winds. This meant that the adopted method in this study is effective in bridging the 10-minute and 1-minute winds from PAGASA and JTWC, respectively, compared to using the recommendation from WMO.

Despite this improvement in converting 10-minute winds to 1-minute winds and vice versa, the discrepancy is not fully addressed. In the case of Meranti in Fig. 13, there remains a difference in terms of timing and rate of intensification between the 10-minute winds of PAGASA and the 10-minute derived winds from JTWC using the conditional CI number method. For instance, prior to 00 UTC 


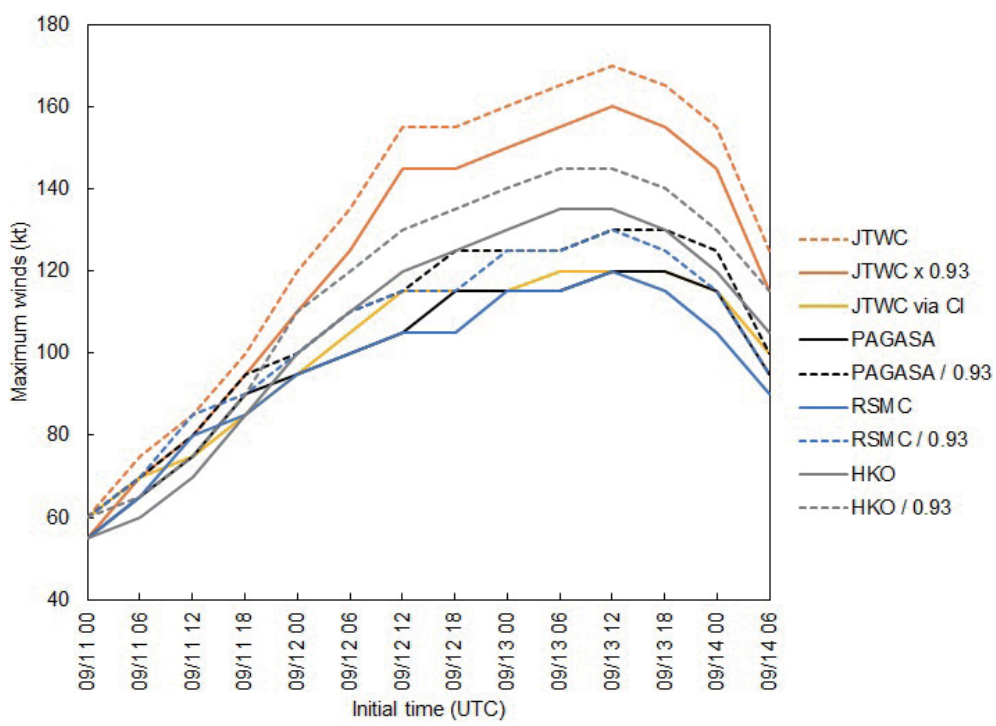

Fig. 13. Time series of maximum winds of Typhoon Meranti within the PAR region from 00 UTC 11 of September to 06 UTC of 14 September expressed at 10-minute averaging from PAGASA, RSMC Tokyo, and HKO and at 1-minute averaging from JTWC. The time series also include 10-minute winds converted from JTWC using both the conditional CI number method and the 0.93 multiplier and 1-minute winds converted from PAGASA, RSMC Tokyo, and HKO estimates using the 0.93 multiplier. Solid lines are 10-minute winds while dashed lines are 1-minute winds.

of 12 September, Meranti was intensifying slightly faster in PAGASA winds than in JTWC 10-minute winds. However, past 00 UTC of 12 September, JTWC 10-minute winds surpassed PAGASA estimates, with the former reaching 115-kt winds $12 \mathrm{~h}$ earlier than the latter. Previous studies involving WNP tropical cyclone best tracks (i.e., Knapp and Kruk 2010; Barcikowska et al. 2012) revealed that converting between wind speed averaging using either of the methods do not fully address the discrepancy with JTWC still having significantly higher wind estimates than RSMC Tokyo and other agencies using the K91 table especially for the stronger storms. Song et al. (2010) observed a significant increase in the annual average difference between the two intensity datasets since 1977 , roughly during the period when aircraft reconnaissance was terminated in the WNP, with RSMC Tokyo having weaker intensity estimates than JTWC. Such increasing difference may further worsen the remaining discrepancy between JTWC 1-minute winds and 10-minute winds from most TC warning centers.

Possible explanations for the remaining discrepancies include the differences in the emphasis and consistency in using surface observations (SYNOP, SHIP, and BUOY), polar-orbiting satellite (including scatterometer-derived winds data), and objective methods such as the Advanced Dvorak Technique (Olander and Velden 2007), AMSUbased estimates (Brueske and Velden 2003; Demuth et al. 2004, 2006; Herndon et al. 2004), and Satellite Consensus Intensity (SATCON) approach (Herndon and Velden 2018) to supplement the intensity estimate from the Dvorak technique (Barcikowska et al. 2012; Velden et al. 2012) and the subjectivity and regional differences (i.e., rules constraining changes in CI number during intensification, weakening, and landfall) in the Dvorak technique that lead to discrepancies in the Dvorak parameters (Koba et al. 1989, 1991; Nakazawa and Hoshino 2009; Shum and Chan 2013; Koide and Nishimura 2017).

To have an idea on the effect of the remaining discrepancy between 1-minute winds from JTWC and the 1-minute winds derived from PAGASA 10-minute estimates, the WAIP was initialized at 12 UTC of 12 September to generate 1-minute wind forecast up to $96 \mathrm{~h}$. PAGASA best track data shows that at this initial time, Meranti had 10-minute maximum winds of $54 \mathrm{~m} \mathrm{~s}^{-1}$. The nominal conversion factor of 0.93 (Harper et al. 2010) yields an equivalent 1-minute winds of $58 \mathrm{~m} \mathrm{~s}^{-1}$ while the use of conditional CI number method yields an equivalent 1-minute winds of $71 \mathrm{~m} \mathrm{~s}^{-1}$. Despite this conversion, these were 9 to $22 \mathrm{~m} \mathrm{~s}^{-1}$ lower than 1 -minute winds of $80 \mathrm{~m} \mathrm{~s}^{-1}$ from the JTWC. This shows that the available methods of interconversion do not fully address the discrepancy between wind speed values of different averaging times.

Figure 14 presents the time series of forecast maximum winds at 1-minute averaging at 12 UTC of 12 September for Typhoon Meranti using the two derived 1-minute winds and the JTWC 1-minute winds as input wind speed of the model. Using $80 \mathrm{~m} \mathrm{~s}^{-1}$ as initial intensity (Exp1), the WAIP predicted a slight increase in intensity at $12 \mathrm{~h}$ to $81 \mathrm{~m} \mathrm{~s}^{-1}$ followed by a period of continuous weakening at an average 24-h rate of $13.4 \mathrm{~m} \mathrm{~s}^{-1}$. From $81 \mathrm{~m} \mathrm{~s}^{-1}$ at $12 \mathrm{~h}$, WAIP predicted the intensity to drop below typhoon strength at $28 \mathrm{~m} \mathrm{~s}^{-1}$ by $120 \mathrm{~h}$. In comparison, the WAIP forecast using $71 \mathrm{~m} \mathrm{~s}^{-1}$ as initial intensity (Exp2) had increasingly 


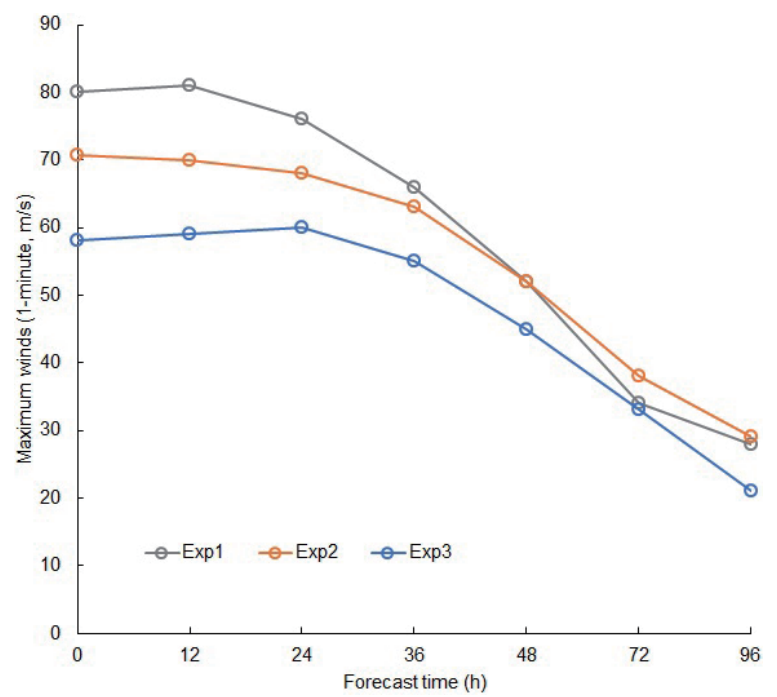

Fig. 14. Time series of forecast 1-minute maximum winds from WAIP for Typhoon Meranti at 12 UTC 12 September using different input winds: 1-minute winds from JTWC (Exp1) and 10-minute winds from PAGASA remapped to 1-minute averaging using the conditional CI number method (Exp2) and the recommended conversion factor by Harper et al. (2010) (Exp3).

weakening trend, with forecast intensities at the 12-h to $36-\mathrm{h}$ period that were 3 to $11 \mathrm{~m} \mathrm{~s}^{-1}$ lower than those generated by WAIP if JTWC 1-minute winds is used. At $48 \mathrm{~h}$, Exp2 predicted the same 1-minute winds as Exp1 while at 72 and $96 \mathrm{~h}$, Exp2 predicted 1 to $4 \mathrm{~m} \mathrm{~s}^{-1}$ higher winds than Exp 1. The WAIP run that used $58 \mathrm{~m} \mathrm{~s}^{-1}$ as initial intensity (Exp3) had a trend similar to Exp 1, with a brief period of slight intensification followed by an increasingly weakening trend. However, the intensity forecast from Exp3 was the lowest among the three initializations across all forecast intervals, with maximum winds that were 1 to $22 \mathrm{~m} \mathrm{~s}^{-1}$ lower than the corresponding predictions from Exp1.

Figure 15 shows that the tracks and intensity evolutions of the historical analogs selected by the model for Exp1, Exp2, and Exp3 were different. The mean $d_{T}$ of the 10 analogs for Exp1, Exp2, and Exp3 were 3.5, 3.0, and 2.6 , respectively. Although the analogs for the three experiments had a generally west-northwestward to northwestward track, Exp1 and Exp2 shared more resemblance, with the analogs generally clustered into two groups - those that crossed Taiwan and those that passed over Luzon Strait or crossed the northern portion of northern Luzon. On the other hand, Exp3 also exhibited two groupings - those that either crossed Central-Southern Taiwan or passed over Luzon Strait and those that crossed northern Luzon. Most of the analogs from the three experiments had similar trends - an initial period (up to $36 \mathrm{~h}$ ) wherein the analog either slightly intensified or maintained strength, followed by a period of continuous weakening. However, the intensity evolutions varied considerably due to the differences in the input winds per experiment.

Table 3 lists the top 10 analogs selected by WAIP for Exp1, Exp2, and Exp3. Because the initial intensity of
Exp2 $\left(71 \mathrm{~m} \mathrm{~s}^{-1}\right.$, from PAGASA 10-minute winds converted to 1-minute using the conditional CI number method) was closer to Exp1 (80 $\mathrm{m} \mathrm{s}^{-1}$, JTWC 1-minute winds) than Exp3 $\left(58 \mathrm{~m} \mathrm{~s}^{-1}\right.$, from PAGASA 10-minute winds converted to 1-minute using 0.93 multiplier), Exp2 had more analogs that were also used in Exp1 than Exp3. In particular, seven of the 10 analogs of Exp2 were also used by WAIP in Exp1, with the top two analogs of both experiments being in the same ranking (wp172013 at rank 1 and wp092007 at rank 2). In comparison, Exp1 and Exp3 shared only one similar analog, wp171968. Despite the similarities in the analogs of Exp1 and Exp2, the remaining discrepancy between the initial intensities even after the conversion of PAGASA 10-minute winds to 1-minute (using the conditional CI number method) to match the 1-minute winds of JTWC still resulted to differences in the intensity forecast of WAIP as seen in Fig. 14.

\section{SUMMARY AND CONCLUDING REMARKS}

Improvements in the track forecast guidance has led to the increased reliability of intensity forecast from statistical, dynamical, and statistical-dynamical TC intensity forecast models. Under the premise that the TC track is the primary determinant of the intensity on 5-day timescale or longer, a statistical intensity forecast model called Weighted Ana$\log$ Intensity Prediction (WAIP) has been developed for the WNP (Tsai and Elsberry 2014). It is based on the rankedweighted mean of 10 best historical analogs from the JTWC 1945 - 2014 best tracks wherein the ranking was determined from the similarity of each analog to the reference track forecast and initial intensity of the TC of interest provided by the TC warning center. The performance of the model 
(a)

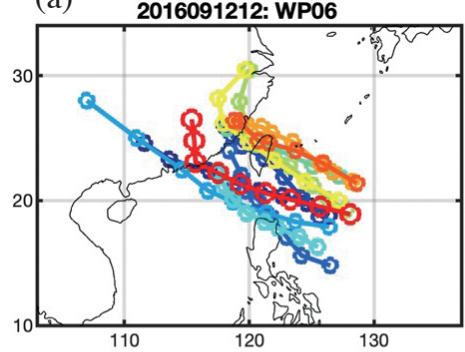

(b)

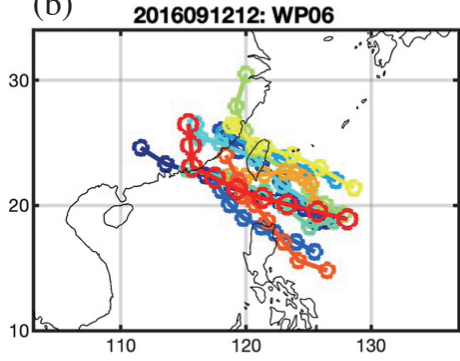

(c)

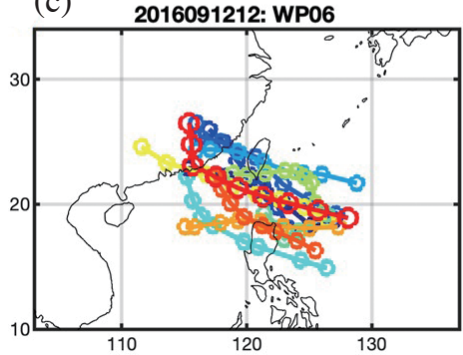

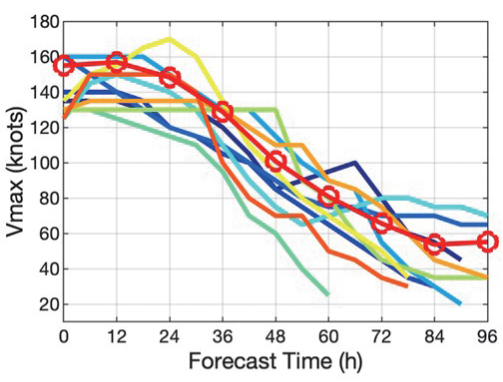
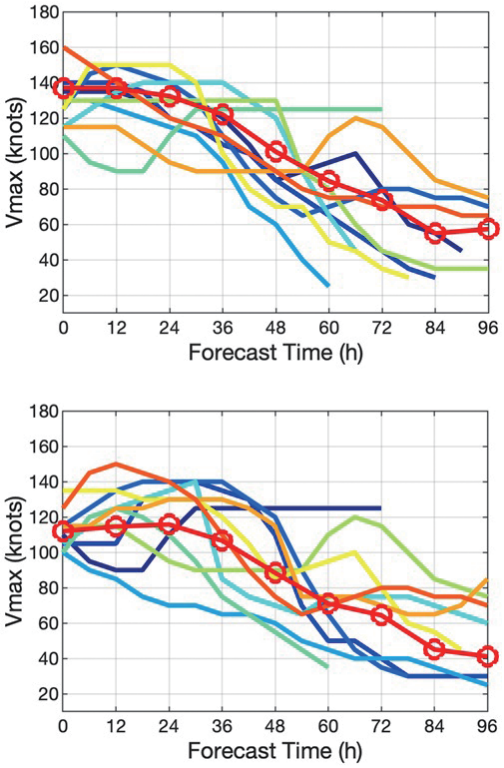

Fig. 15. Tracks (left) and intensity evolutions (right) of the historical analogs from the JTWC best track database that were used in the WAIP intensity forecast at 12 UTC on 12 September for Typhoon Meranti: (a) Exp1, (b) Exp2, (c) Exp3. The red lines and markers indicate the reference track forecast (left) and the resulting WAIP intensity forecast (right). Each analog is differentiated by color. Maximum winds are in 1-minute averaging.

Table 3. The ranking of historical analogs used by WAIP in its forecast for Typhoon Meranti initialized at 12 UTC on 12 September. Exp1 to Exp3 are different runs of the same forecast that only differed in the input initial intensity (at 1-minute averaging). Analogs with single asterisks are analogs of Exp2 or 3 that were also used by WAIP in Exp1.

\begin{tabular}{|c|c|c|c|}
\hline Rank & $\begin{array}{c}\text { Exp1 } \\
\text { JTWC 1-minute }\end{array}$ & $\begin{array}{c}\text { Exp2 } \\
\text { PAGASA 1-minute using conditional CI number method }\end{array}$ & $\begin{array}{c}\text { Exp3 } \\
\text { PAGASA 1-minute using constant } 0.93 \text { factor }\end{array}$ \\
\hline 1 & wp172013 & wp172013* & wp121953 \\
\hline 2 & wp092007 & wp092007* & wp141956 \\
\hline 3 & wp171973 & wp171968* & wp182000 \\
\hline 4 & wp211964 & wp132005* & wp151992 \\
\hline 5 & wp171968 & wp182000 & wp141970 \\
\hline 6 & wp132005 & wp121953 & wp181967 \\
\hline 7 & wp171962 & wp171962* & wp152012 \\
\hline 8 & wp091959 & wp191965* & wp172013 \\
\hline 9 & wp141963 & wp152012 & wp261989 \\
\hline 10 & wp191965 & wp171973* & wp171968* \\
\hline
\end{tabular}


against both JTWC official and dynamical model guidance (Tsai and Elsberry 2014, 2016), as well as its low demand for computation resources makes it a viable guidance for intensity prediction. A seven-day version of WAIP has since been developed (Tsai and Elsberry 2015a) for the JTWC.

With PAGASA considering the issuance of intensity forecasts for TCs within the PAR region, the intensity forecasts from the seven-day version of WAIP were evaluated to serve as the initial verification study that will increase the confidence of Filipino typhoon forecasters in utilizing the model as a baseline intensity guidance. Using the PAGASA track forecast as the reference track forecast, a total of 629 intensity forecasts from $63 \mathrm{TC}$ events that entered that PAR between January 2014 and December 2017 with maximum forecast length of three to five days were generated by the WAIP integrated into the PAGASA forecast support system PISTON. Due to differences in the wind averaging periods of the JTWC best track used by the WAIP and input winds at initial times, the 10-minute input winds are remapped to 1-minute winds while the forecast 1-minute wind values from WAIP are converted to their equivalent in 10-minute averaging using the conditional $\mathrm{CI}$ number method.

WAIP was found to have positive intensity bias at all forecast times with the magnitude of bias being consistently smaller than persistence at all forecast times except at $120 \mathrm{~h}$. However, the values for the samples limited in the PAR region did not follow those of Tsai and Elsberry (2014) wherein forecast biases for most forecast times were below $0.5 \mathrm{~m} \mathrm{~s}^{-1}$. Compared to persistence, the intensity forecasts from WAIP had significantly smaller MAE at 12 to $96 \mathrm{~h}$ forecast intervals with roughly $52 \%$ reduction in MAE at $72 \mathrm{~h}$ with respect to persistence. However, noting the small sample size at the 96-h interval brought by the limitations in terms of the extent of the reference track forecast and the best track data from PAGASA, these metrics imply the skill of WAIP relative to persistence in providing intensity forecast at 12-h to 72-h periods. The trend in the MAE values was found to be similar to those of Tsai and Elsberry (2014) except that in this study, the MAE rapidly increased beyond $72 \mathrm{~h}$. The behavior at these forecast intervals was attributed to the small sample size associated with the truncation in the reference forecast track and best track data of PAGASA within the PAR region until 2017 and the absence of 5-day track forecast in 2014 and some of 2015 TC cases. The small sample size also resulted in the MAE difference between WAIP and persistence at $120 \mathrm{~h}$ being statistically insignificant. As such, the complete picture of the performance at 96 and $120 \mathrm{~h}$ within the PAR region cannot be inferred from this investigation.

The examination of probability distribution of intensities at 36, 72, and $96 \mathrm{~h}$ predicted by the model showed that the WAIP, as a statistical model, does not fully capture the full range of the observed intensities or of the extreme values, with the model struggling to predict lower range of intensity values with increasing forecast intervals. The cases of Typhoon Maysak in 2015 and Typhoons Talim and Tembin in 2017 demonstrated the dependence of WAIP as a statistical-analog method of prediction on the accuracy of the reference track forecast, the number of available historical analogs for a particular forecast scenario, and the degree of resemblance of these analogs to the reference track forecast.

Previous investigations (i.e., Knapp and Kruk 2010; Song et al. 2010; Barcikowska et al. 2012) revealed that maximum winds at 1-minute averaging from JTWC had notable discrepancies against 10-minute winds from the RSMC Tokyo. Moreover, such discrepancies remain irreconcilable because the difference in intensity estimates between these two centers stem out from the difference not just in the intensity lookup tables being used to convert Dvorak-derived CI number to maximum speed, but also in the regional differences in the application of Dvorak technique and the emphasis of each center in the use of other meteorological data in the determination of maximum winds. Lastly, a growing difference in maximum winds between JTWC and JMA best track dataset since 1977 reinforces the irreconcilability of these values. With PAGASA sharing the same method of intensity estimation as the RSMC Tokyo, notably in the adoption of K91 lookup table, the use of JTWC best track as a source of historical analogs poses a potential issue with the WAIP. Using Typhoon Meranti as an example, it was demonstrated that even with the use of interconversion approaches such as the conditional $\mathrm{CI}$ number method and the WMO-recommended nominal multiplier, there is still a discrepancy between JTWC 1-minute winds and the 1-minute winds derived from the PAGASA 10-minute winds. Such discrepancy leads to inconsistency in the generated forecast by the WAIP. In the case of Meranti, the forecast intensities generated using PAGASA 1-minute derived winds was lower than those generated when JTWC 1-minute winds are used.

The influence of using JTWC best track on the intensity spread forecast produced by WAIP must be looked in future studies as this product is intended to inform forecasters of the magnitude of uncertainty in an intensity forecast, especially when the historical analogs used by WAIP exhibited rapid changes in intensity (i.e., rapid intensification or weakening) or extended periods of non-intensification - situations wherein WAIP generated less satisfactory forecasts in previous studies (Tsai and Elsberry 2014, 2015a). The potential use of other best track datasets such as those from the RSMC Tokyo as the source of historical analogs and its impact on the observed bias in the intensity forecasts generated by WAIP must be explored. Furthermore, given the developments in the weighted analog technique over the last 5 years (Tsai and Elsberry 2015a, b, 2017a, 2018, 2019), the existing algorithm of the WAIP module built into PISTON must be updated and its performance investigated with due consideration to the use of other best track sources. 
Since 2018, PAGASA has extended its monitoring domain for TCs and now truncates its official TC forecasts within the region of $4-28^{\circ} \mathrm{N}$ and $114-145^{\circ} \mathrm{E}$ instead of the PAR region only. Furthermore, its best track data has been extended to include the entire duration of TC (i.e., from genesis to weakening into remnant low or transitioning to extratropical cyclone). These improvements will increase the number of samples at higher forecast times in future verification studies of WAIP. The bias correction scheme in the current WAIP may also need revisions to further improve its performance within the PAR region, especially in cases of rapid changes in intensity.

Tsai and Elsberry (2016) identified that while the three numerical models had no skill relative to WAIP as an intensity forecast and especially beyond 72-h forecast interval, statistical-dynamical consensus method significantly outperformed the intensity forecasts of WAIP especially at forecast times up to $72 \mathrm{~h}$ and in landfalling situations along the coast of China, Southeast Asia, and northeastern Japan across all forecast times. Moreover, DeMaria et al. (2014) also noted that statistical-dynamical methods and consensus methods performed better than statistical and dynamical guidance in intensity forecast in the WNP basin. In a separate investigation, the intensity forecasts from the new statistical-dynamical guidance of the RSMC Tokyo (Yamaguchi et al. 2018; Ono et al. 2019) were generally more accurate than those made with its own global NWP model (Global Spectral Model) and the Statistical Hurricane Intensity Forecast (Jarvinen and Neumann 1979) despite the observed overestimation of TC intensity in the genesis stage, slow response in rapid intensity changes, and unsuitability in cases of extratropical cyclones transitioning back to TCs. Such developments suggest future undertakings involving intensity forecasts using statistical-dynamical and consensus methods for Philippine TCs to increase the confidence of PAGASA forecasters in providing official intensity forecasts.

Acknowledgements This work was supported by a grant funded by the Department of Science and Technology (DOST) through the Philippine Council for Industry, Energy and Emerging Technology Research and Development (PCIEERD) under a collaborative research program between the Philippines and Taiwan (MECO-TECO VOTE Meteorology Program I). We sincerely appreciate the constructive comments and suggestions made by the anonymous reviewers to improve the quality of this work. We also thank Ms. Ella Marie M. Soriano (PAGASA) for copyreading the manuscript. Statistical calculations used in this study were performed using jamovi v1.2 (https://www.jamovi.org).

\section{REFERENCES}

Barcikowska, M., F. Feser, and H. von Storch, 2012: Usability of Best Track Data in Climate Statistics in the
Western North Pacific. Mon. Weather Rev., 140, 28182830, doi: 10.1175/MWR-D-11-00175.1. [Link]

Brueske, K. F. and C. S. Velden, 2003: Satellite-Based Tropical Cyclone Intensity Estimation Using the NOAA-KLM Series Advanced Microwave Sounding Unit (AMSU). Mon. Weather Rev., 131, 687-697, doi: 10.1175/1520-0493(2003)131<0687:SBTCIE >2.0. CO;2. [Link $]$

Burton, A. and C. Velden, 2016: International Workshop on Satellite Analysis of Tropical Cyclones II (IWSATCII): Report and Recommendations, World Meteorological Organization, $10 \mathrm{pp}$. Available at https://library. wmo.int/doc num.php?explnum id=6430.

DeMaria, M., C. R. Sampson, J. A. Knaff, and K. D. Musgrave, 2014: Is Tropical Cyclone Intensity Guidance Improving? Bull. Amer. Meteorol. Soc., 95, 387-398, doi: 10.1175/BAMS-D-12-00240.1. [Link]

Demuth, J. L., M. DeMaria, J. A. Knaff, and T. H. Vonder Haar, 2004: Evaluation of Advanced Microwave Sounding Unit Tropical-Cyclone Intensity and Size Estimation Algorithms. J. Appl. Meteorol. Climatol., 43, 282-296,doi: 10.1175/1520-0450(2004)043<0282:EOAMSU>2.0.CO;2. [Link]

Demuth, J. L., M. DeMaria, and J. A. Knaff, 2006: Improvement of Advanced Microwave Sounding Unit Tropical Cyclone Intensity and Size Estimation Algorithms. J. Appl. Meteorol. Climatol., 45, 1573-1581, doi: 10.1175/JAM2429.1. [Link]

Dvorak, V. F., 1984: Tropical cyclone intensity analysis using satellite data. NOAA Technical Report NESDIS 11, NOAA-S/T 84-232, Data, and Information Service, National Environmental Satellite, United States, 50 pp.

Elsberry, R. L. and H.-C. Tsai, 2014: Situation-dependent intensity skill metric and intensity spread guidance for western North Pacific tropical cyclones. Asia-Pac. J. Atmos. Sci., 50, 297-306, doi: 10.1007/s13143-0140018-5. [Link]

Harper, B. A., J. D. Kepert, and J. D. Ginger, 2010: Guidelines for converting between various wind averaging periods in tropical cyclone conditions. WMO/TD No. 1555, World Meteorological Organization, 54 pp. Available at https://www.wmo.int/pages/prog/www/ tcp/documents/WMO TD 1555 en.pdf.

Herndon, D. and C. S. Velden, 2018: An Update on the CIMSS SATellite CONsensus (SATCON) Tropical Cyclone Intensity Algorithm. 33rd Conference on Hurricanes and Tropical Meteorology, Ponte Vedra Beach, FL. Available at https://ams.confex.com/ ams/33HURRICANE/webprogram/Paper340235.html.

Herndon, D. C., C. S. Velden, K. Brueske, R. Wacker, and B. Kabat, 2004: Upgrades to the UW-CIMSS AMSUbased tropical cyclone intensity estimation algorithm. Preprints, 26th Conference on Hurricanes and Tropical Meteorology, Miami, FL, 2 pp. 
Japan Meteorological Agency, 2016: Annual Report on the Activities of the RSMC Tokyo - Typhoon Center 2015, Japan Meteorological Agency, 103 pp. Available at http://www.jma.go.jp/jma/jma-eng/jma-center/rsmchp-pub-eg/AnnualReport/2015/Text/Text2015.pdf.

Japan Meteorological Agency, 2018: Annual Report on the Activities of the RSMC Tokyo - Typhoon Center 2017, Japan Meteorological Agency, 105 pp. Available at http://www.jma.go.jp/jma/jma-eng/jma-center/rsmchp-pub-eg/AnnualReport/2017/Text/Text2017.pdf.

Jarvinen, B. R. and C. J. Neumann, 1979: Statistical forecasts of tropical cyclone intensity for the North Atlantic basin. NOAA Technical Memorandum NWS NHC10, 22 pp. Available at https://www.nhc.noaa.gov/pdf/ NWS-NHC-1979-10.pdf.

Kirch, L., S. Luther, P. Mucke, R. Prütz, K. Radtke, and C. Schrader, 2017: WorldRiskReport: Analysis and Prospects 2017, Bündnis Entwicklung Hilft, 47 pp.

Knaff, J. A., M. DeMaria, C. R. Sampson, and J. M. Gross, 2003: Statistical, 5-Day Tropical Cyclone Intensity Forecasts Derived from Climatology and Persistence. Weather Forecast., 18, 80-92, doi: 10.1175/1520-0434(2003)018<0080:SDTCIF $>2.0$. CO;2. [Link]

Knapp, K. R. and M. C. Kruk, 2010: Quantifying interagency differences in tropical cyclone best-track wind speed estimates. Mon. Weather Rev., 138, 1459-1473, doi: 10.1175/2009MWR3123.1. [Link]

Koba, H., S. Osano, T. Hagiwara, S. Akashi, and T. Kikuchi, 1989: Determination of the intensity of typhoons passing over the Philippines (in Japanese). J. Meteor. Res., 41, 157-162.

Koba, H., T. Hagiwara, S. Osano, and S. Akashi, 1991: Relationships between $\mathrm{CI}$ number and minimum sea level pressure/maximum wind speed of tropical cyclones. Geophys. Mag., 44, 15-25.

Koide, N. and S. Nishimura, 2017: Comparative Study of Dvorak Analysis in the western North Pacific. Technical Review No. 19, RSMC Tokyo - Typhoon Center, 26 pp. Available at http://www.jma.go.jp/jma/jmaeng/jma-center/rsmc-hp-pub-eg/techrev/text19-1.pdf.

Krayer, W.R. and R. D. Marshall, 1992: Gust factors applied to hurricane winds. Bull. Amer. Meteorol. Soc., 73, 613-618, doi: 10.1175/1520-0477(1992)073<0613:GF ATHW $>2.0 . C O ; 2$. [Link]

Maue, R. N., 2011: Recent historically low global tropical cyclone activity. Geophys. Res. Lett., 38, L14803, doi: 10.1029/2011GL047711. [Link]

Mei, W. and S.-P. Xie, 2016: Intensification of landfalling typhoons over the northwest Pacific since the late 1970s. Nat. Geosci., 9, 753-757, doi: 10.1038/ ngeo2792. [Link]

Nakazawa, T. and S. Hoshino, 2009: Intercomparison of Dvorak Parameters in the Tropical Cyclone Datasets over the Western North Pacific. SOLA, 5, 33-36, doi: 10.2151/sola.2009-009. [Link]

Olander, T. L. and C. S. Velden, 2007: The Advanced Dvorak Technique: Continued Development of an Objective Scheme to Estimate Tropical Cyclone Intensity Using Geostationary Infrared Satellite Imagery. Weather Forecast., 22, 287-298, doi: 10.1175/ WAF975.1. [Link]

Ono, M., S. Notsuhara, J. Fukuda, Y. Igarashi, and K. Bessho, 2019: Operational Use of the Typhoon Intensity Forecasting Scheme Based on SHIPS (TIFS) and Commencement of Five-day Tropical Cyclone Intensity Forecasts. Technical Review No. 21, RSMC Tokyo - Typhoon Center, 17 pp. Available at http://www. jma.go.jp/jma/jma-eng/jma-center/rsmc-hp-pub-eg/ techrev/text21-2.pdf.

PAGASA, 2019: DOST-PAGASA Annual Report on Philippine Tropical Cyclones 2017, Weather Division, Philippine Atmospheric, Geophysical and Astronomical Services Administration (PAGASA), Department of Science and Technology (DOST), Philippines, $76 \mathrm{pp}$.

Sampson, C. R. and A. J. Schrader, 2000: The Automated Tropical Cyclone Forecasting System (Version 3.2). Bull. Amer. Meteorol. Soc., 81, 1231-1240, doi: 10.1175/1520-0477(2000)081<1231:TATCFS >2.3. CO;2. [Link]

Sampson, C. R., R. A. Jeffries, C. J. Neumann, and J.-H. Chu, 1995: Tropical Cyclone Forecasters Reference Guide: 6. Tropical Cyclone Intensity. NRL Report NRL/PU/754195-0012, Naval Research Laboratory, 48 pp.

Shum, C. T. and S. T. Chan, 2013: Application of Dvorak Technique During the Weakening Stage of Tropical Cyclones. Trop. Cyclone Res. Rev., 2, 207-221, doi: 10.6057/2013TCRR04.03. [Link]

Simiu, E. and R. H. Scanlan, 1978: Wind Effects on Structures: An introduction to wind engineering, Wiley-Interscience, $458 \mathrm{pp}$.

Song, J.-J., Y. Wang, and L. Wu, 2010: Trend discrepancies among three best track data sets of western North $\mathrm{Pa}$ cific tropical cyclones. J. Geophys. Res., 115, D12128, doi: 10.1029/2009JD013058. [Link]

Tsai, H.-C. and Y. L. Chen, 2010: Utilizing the track analog and the reanalysis data to support typhoon climatological rainfall forecasts. Conf. Wea. Analysis and Forecasting, Central Weather Bureau, Taipei, Taiwan.

Tsai, H.-C. and R. L. Elsberry, 2014: Applications of situation-dependent intensity and intensity spread predictions based on a weighted analog technique. Asia-Pac. J. Atmos. Sci., 50, 507-518, doi: 10.1007/s13143-0140040-7. [Link]

Tsai, H.-C. and R. L. Elsberry, 2015a: Seven-day intensity and intensity spread predictions for western North Pacific tropical cyclones. Asia-Pac. J. Atmos. Sci., 51, 331-342, doi: 10.1007/s13143-015-0082-5. [Link] 
Tsai, H.-C. and R. L. Elsberry, 2015b: Weighted Analog Technique for Intensity and Intensity Spread Predictions of Atlantic Tropical Cyclones. Weather Forecast., 30, 1321-1333, doi: 10.1175/WAF-D-15-0030.1. [Link]

Tsai, H.-C. and R. L. Elsberry, 2016: Skill of western North Pacific tropical cyclone intensity forecast guidance relative to Weighted-Analog technique. Asia-Pac. J. Atmos. Sci., 52, 281-290, doi: 10.1007/s13143-0160001-4. [Link]

Tsai, H.-C. and R. L. Elsberry, 2017a: Ending Storm Version of the 7-day Weighted Analog Intensity Prediction Technique for Western North Pacific Tropical Cyclones. Weather Forecast., 32, 2229-2235, doi: 10.1175/WAF-D-17-0151.1. [Link]

Tsai, H.-C. and R. L. Elsberry, 2017b: Seven-Day Intensity and Intensity Spread Predictions for Atlantic Tropical Cyclones. Weather Forecast., 32, 141-147, doi: 10.1175/WAF-D-16-0165.1. [Link]

Tsai, H.-C. and R. L. Elsberry, 2018: Seven-Day Intensity and Intensity Spread Predictions in Bifurcation Situations with Guidance-On-Guidance for Western North Pacific Tropical Cyclones. Asia-Pac. J. Atmos. Sci., 54, 421-430, doi: 10.1007/s13143-018-0008-0. [Link]

Tsai, H.-C. and R. L. Elsberry, 2019: Combined ThreeStage 7-Day Weighted Analog Intensity Prediction Technique for Western North Pacific Tropical Cyclones: Demonstration of Optimum Performance. Weather Forecast., 34, 1979-1998, doi: 10.1175/ WAF-D-19-0130.1. [Link]

Velden, C., B. Harper, F. Wells, J. L. Beven, R. Zehr, T. Olander, M. Mayfield, C. Guard, M. Lander, R. Edson, L. Avila, A. Burton, M. Turk, A. Kikuchi, A. Chris- tian, P. Caroff, and P. McCrone, 2006: The Dvorak Tropical Cyclone Intensity Estimation Technique: A Satellite-Based Method that Has Endured for over 30 Years. Bull. Amer. Meteorol. Soc., 87, 1195-1210, doi: 10.1175/BAMS-87-9-1195. [Link]

Velden, C., A. Burton, and K. Kuroiwa, 2012: The First International Workshop on Satellite Analysis of Tropical Cyclones: Summary of Current Operational Methods to Estimate Intensity. Trop. Cyclone Res. Rev., 1, 469481, doi: 10.6057/2012TCRR04.05. [Link]

Weinkle, J., R. Maue, and R. Pielke, 2012: Historical Global Tropical Cyclone Landfalls. J. Clim., 25, 4729-4735, doi: 10.1175/JCLI-D-11-00719.1. [Link]

Wilks, D. S., 2011: Statistical Methods in the Atmospheric Sciences, Volume 100, 3rd Edition, Academic Press, $704 \mathrm{pp}$.

Wong, W.-K. and C.-W. Choy, 2018: Progress in Hong Kong's Tropical Cyclone Forecasting and Warning Services in Recent Decades. Trop. Cyclone Res. Rev., 7, 37-50, doi: 10.6057/2018TCRR01.05. [Link]

World Meteorological Organization, 2020: Typhoon Committee Operational Manual: Meteorological Component. Technical Document WMO/TD-No. 196, Tropical Cyclone Programme Report No. TCP-23, World Meteorological Organization, 139 pp. Available at https://wmoomm.sharepoint.com/:b:/s/wmocpdb/ EUAD9RzQvapAkGuDG991LYoBKmCZlMkwQEg $\underline{X d m 4 q Q 1 v 3 A}$ ?e=L6mzNA2020.

Yamaguchi, M., H. Owada, U. Shimada, M. Sawada, T. Iriguchi, K. D. Musgrave, and M. DeMaria, 2018: Tropical Cyclone Intensity Prediction in the Western North Pacific Basin Using SHIPS and JMA/GSM. SOLA, 14, 138-143, doi: 10.2151/sola.2018-024. [Link] 